\title{
U.S./EURATOM INERI - Development of Inert Matrix Fuels for Plutonium and Minor Actinide Management in LWRs -- Fuel Requirements and Down-Select Report
}

William Carmack

Randy Fielding

Pavel Medvedev

Mitch Meyer

Michael Todosow

Joseph Somers

Didier Haas

A. Fernandez

August 2005

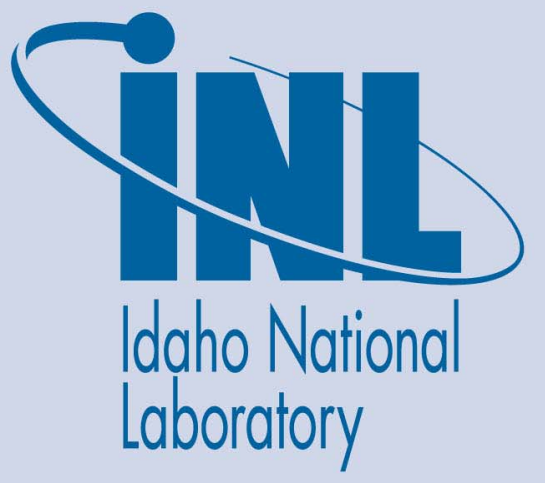

The INL is a U.S. Department of Energy National Laboratory operated by Battelle Energy Alliance 
INL/EXT-05-00562

\title{
U.S./EURATOM INERI - Development of Inert Matrix Fuels for Plutonium and Minor Actinide Management in LWRs - Fuel Requirements and Down-Select Report
}

\author{
William Carmack ${ }^{\mathrm{a}}$ \\ Randy Fielding ${ }^{a}$ \\ Pavel Medvedev ${ }^{\mathrm{a}}$ \\ Mitch Meyer $^{\mathrm{a}}$ \\ Michael Todosow ${ }^{b}$ \\ Joseph Somers ${ }^{c}$ \\ Didier Haas ${ }^{\mathrm{c}}$
}

A. Fernandez ${ }^{\mathrm{c}}$

${ }^{\mathrm{a}} \mathrm{INL}$

${ }^{\mathrm{b}} \mathrm{BNL}$

${ }^{\mathrm{c}} \mathrm{BTU}$

August 2005

Idaho National Laboratory

Idaho Falls, Idaho 83415

Prepared for the

U.S. Department of Energy

Office of Nuclear Energy

Under DOE Idaho Operations Office

Contract DE-AC07-05ID14517 


\begin{abstract}
This report documents the first milestone of the International Nuclear Energy Research Initiative (INERI) U.S./Canada Joint Proposal entitled "Development of Inert Matrix Fuels for Plutonium and Minor Actinide Management in Power Reactors." The milestone represents the assessment and preliminary study of a variety of fuels that hold promise as transmutation and minor actinide burning fuel compositions for light water reactors. The most promising fuels of interest to the participants on this INERI program have been selected for further study. These fuel compositions are discussed in this report.
\end{abstract}




\section{CONTENTS}

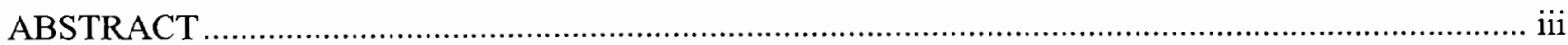

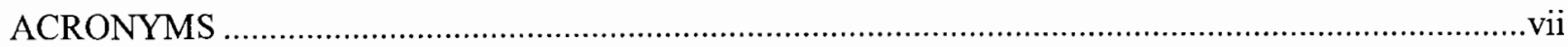

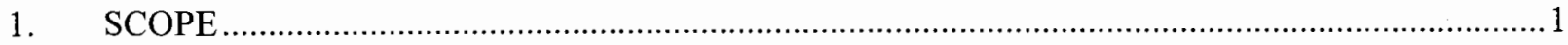

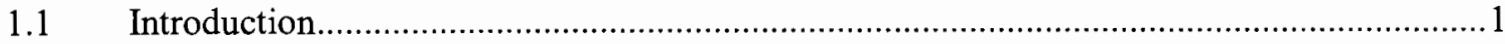

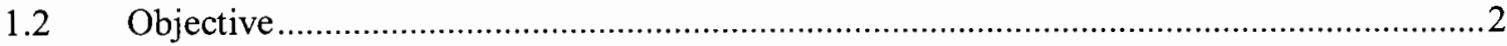

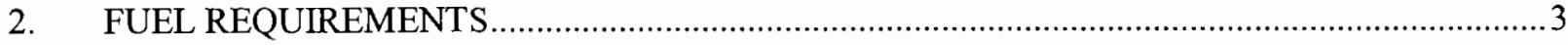

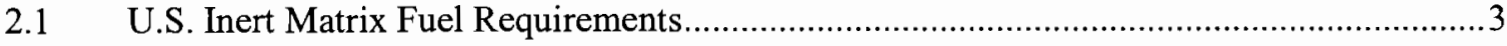

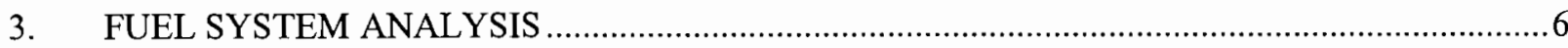

3.1 Neutronic Performance Analysis of Candidate IMF Systems ..........................................6

3.2 Thermal Performance Analysis of Candidate IMF Systems ............................................. 8

3.3 Transient/Safety Analysis of Candidate IMF Systems ................................................. 8

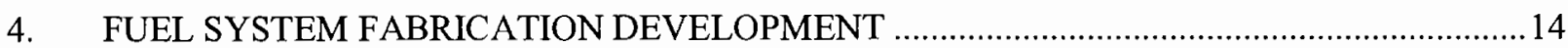

4.1 MOX-Minor Actinide Fuel Development ...................................................................

4.2 Yttria Stabilized Zirconia Inert Matrix Development........................................................ 14

4.3 Dual Phase $\mathrm{MgO}-\mathrm{ZrO}_{2}$ Inert Matrix Development ..........................................................

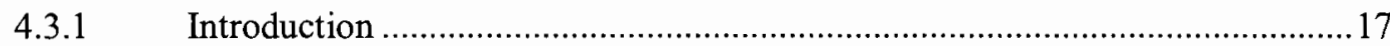

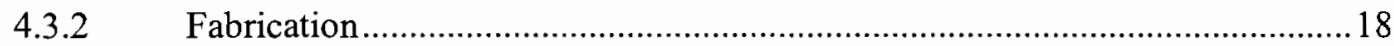

4.3.3 Characterization of $\mathrm{MgO}-\mathrm{ZrO}_{2}-\mathrm{PuO}_{2}$ ceramics ............................................ 19

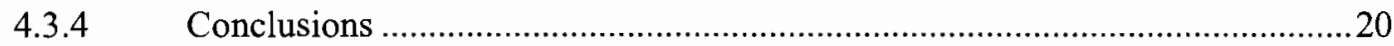

4.4 Zr Metal Inert Matrix Dispersion Fuel Development ......................................................24

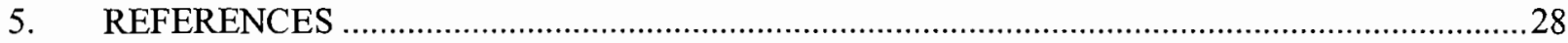

\section{FIGURES}

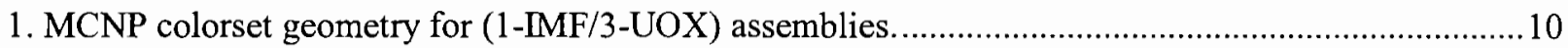

2. Kinf vs. full power day burnup graph comparison with Np-Pu-Am-MOX and UOX........................10

3. Peak clad temperature for hot pin comparison between $\mathrm{MOX}$ and $\mathrm{ZrO}_{2} / \mathrm{MgO}$ and

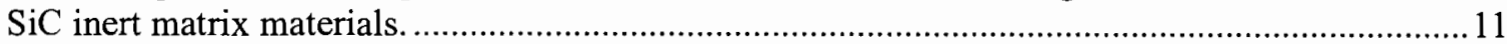

4. Peak clad temperature for hot pin for Loss of Power and Loss of Primary Flow transient..................11

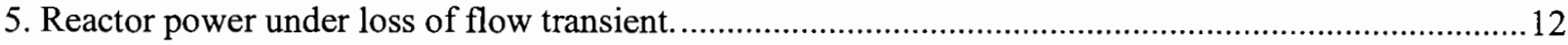

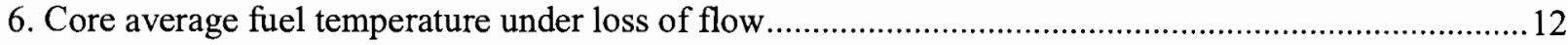

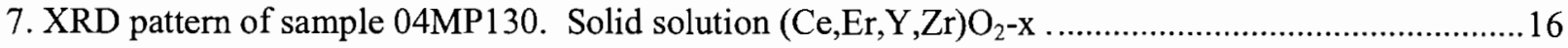

8. Optical micrographs of pellets fabricated by the free-carbon and added carbon route with and without an intermediate milling step. 


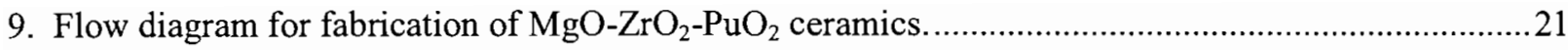

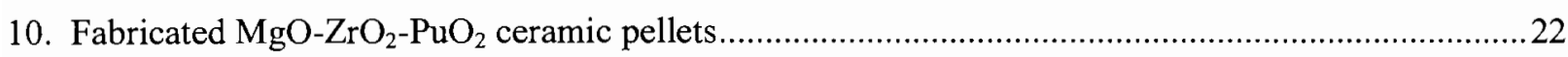

11. SEM image of the $\mathrm{MgO}-\mathrm{ZrO}_{2}-\mathrm{PuO}_{2}$ ceramic sample submitted for analysis .................................22

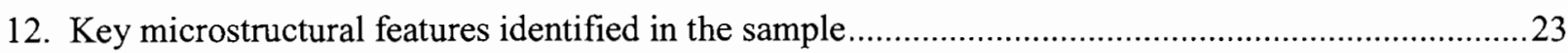

13. Typical EDS spectra observed in various locations in the ceramic..............................................23

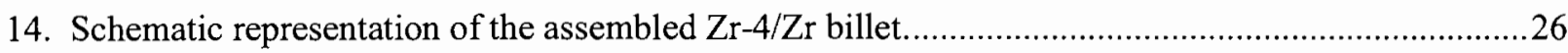

15. Photograph of 0.4-in. diameter Zr matrix dispersion "fuel" extrusion........................................26

16. Photograph of 0.4-in. diameter Zr matrix dispersion "fuel" extrusion longitudinal cross section .......27

17. $\mathrm{UO}_{2}$ spheres produced through rotating electrode atomization..................................................27

\section{TABLES}

1. Proposed compositions to be included in the LWR-2 irradiation test................................................5

2. Reactivity coefficients and control worths for Westinghouse $17 \times 17$ assembly for standard uranium oxide and inert matrix fuels (BOL) . ....................................................................... 7

3. Fuel material thermal-hydraulic characteristics. ..........................................................................

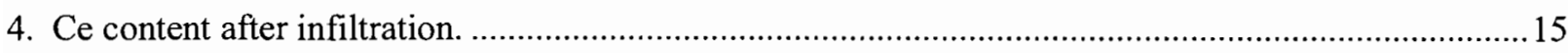

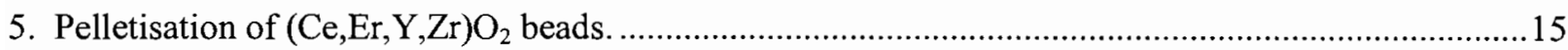

6. Dimensions and weight of the sintered $\mathrm{MgO}-\mathrm{ZrO}_{2}-\mathrm{PuO}_{2}$ ceramic pellets. ..........................................24

7. Results from SEM EDS semi-quantitative analysis. Note that the ISIS EDS system cannot perform quantitative analysis for elements heavier than uranium.....................................24 


\section{ACRONYMS}

\begin{tabular}{ll} 
ACR & Advanced CANDU Reactor \\
AFCI & Advanced Fuel Cycle Initiative \\
EDS & Energy Dispersive X-ray Spectroscopy \\
LWR & light-water reactor \\
IMF & inert-matrix fuel \\
MOX & mixed oxide \\
MTC & moderator temperature coefficient \\
OTTO & once-through then out \\
PCT & peak clad temperature \\
SNF & spent nuclear fuel \\
TRU & transuranic \\
UOX & uranium-oxide \\
YSZ & Yttria stabilized zirconia \\
\hline
\end{tabular}




\title{
U.S./EURATOM INERI - Development of Inert Matrix Fuels for Plutonium and Minor Actinide Management in LWRs
}

\author{
Fuel Requirements and Down-Select Report
}

\section{SCOPE}

\subsection{Introduction}

The U.S. Advanced Fuel Cycle Program and the European Union EURATOM program seek to develop and demonstrate the technologies needed to minimize the overall $\mathrm{Pu}$ and minor actinides present in the light-water reactor (LWR) nuclear fuel cycles. It is proposed to reuse the Pu from LWR spent fuel both for the energy it contains and to decrease the hazard and proliferation impact resulting from storage of the Pu and minor actinides. The use of fuel compositions with a combination of $U$ and $\mathrm{Pu}$ oxide (mixed oxide [MOX]) has been proposed as a way to recycle Pu and/or minor actinides in LWRs. It has also been proposed to replace the fertile $\mathrm{U}^{238}$ matrix of MOX with a fertile-free matrix (inert-matrix fuel [IMF]) to reduce the production of $\mathrm{Pu}^{239}$ in the fuel system. It is important to demonstrate the performance of these fuels with the appropriate mixture of isotopes and determine what impact there might be from trace elements or contaminants. Previous work has already been done to look at weaponsgrade $\mathrm{Pu}$ in the MOX configuration [1][2] and the reactor-grade $\mathrm{Pu}$ in a MOX configuration including small (4000 ppm additions of Neptunium). This program will add to the existing database by developing a wide variety of MOX fuel compositions along with new fuel compositions called inert-matrix fuel (IMF). The goal of this program is to determine the general fabrication and irradiation behavior of the proposed IMF fuel compositions. Successful performance of these compositions will lead to further selection and development of IMF for use in LWRs. This experiment will also test various inert matrix material compositions with and without quantities of the minor actinides Americium and Neptunium to determine feasibility of incorporation into the fuel matrices for destruction.

There is interest in the U.S. and world-wide in the investigation of IMFs for scenarios involving stabilization or burn down of plutonium in the fleet of existing commercial power reactors. IMF offers the potential advantage for more efficient destruction of plutonium and minor actinides relative to MOX fuel. Greater efficiency in plutonium reduction results in greater flexibility in managing plutonium inventories and in developing strategies for disposition of minor actinides, as well as a potential for fuel cycle cost savings. Because fabrication of plutonium-bearing (and minor actinide-bearing) fuel is expensive relative to $\mathrm{UO}_{2}$ in terms of both capital and production, cost benefit can be realized through a reduction in the number of plutonium-bearing elements required for a given burn rate. In addition, the choice of matrix material may be manipulated either to facilitate fuel recycling or to make plutonium recovery extremely difficult. In addition to plutonium/actinide management, an inert matrix fuel having high thermal conductivity may have operational and safety benefits; lower fuel temperatures could be used to increase operating and safety margins, uprate reactor power, or a combination of both.

The CANDU reactor offers flexibility in plutonium management and minor actinides burning by virtue of on-line refueling, a simple bundle design, and good neutron economy. A full core of inert matrix fuel containing either plutonium or a plutonium-actinide mix can be utilized, with plutonium destruction efficiencies greater than $90 \%$, and high $(>60 \%)$ actinide destruction efficiencies. The Advanced CANDU Reactor (ACR) could allow additional possibilities in the design of an IMF bundle, since the tighter lattice pitch and light-water coolant reduce or eliminate the need to suppress coolant void reactivity, allowing the center region of the bundle to include additional fissile material and to improve 
actinide burning. The ACR would provide flexibility for management of plutonium and minor actinides from the existing LWR fleet, and would be complementary to the Advanced Fuel Cycle Initiative (AFCI) program in the U.S. Many of the fundamental principles concerning the use of IMF are nearly identical in LWRs and the ACR, including fuel/coolant compatibility, fuel fabrication, and fuel irradiation behavior. In addition, the U.S. and the European Union both have interest in development of Generation IV supercritical water reactor technology, to which this fuel type would be applicable for plutonium and minor actinides management. An inert matrix fuel with high thermal conductivity would be particularly beneficial to any supercritical water reactor concept. Given these similarities, it is proposed that a joint project be conducted within the framework of a U.S.-EURATOM INERI project on IMF.

\subsection{Objective}

This report will present analysis of the inert matrix fuel compositions of interest for application to U.S. and European LWR fuel cycles, report on the development of fabrication procedures for these compositions, and provide an overview of the test and demonstration plan for these fuel systems.

This report serves in fulfillment of the first deliverable and milestone for the joint INERI program. 


\section{FUEL REQUIREMENTS}

\subsection{U.S. Inert Matrix Fuel Requirements}

Currently, commercial reactors in the U.S. operate on the once-through cycle, with the spent nuclear fuel (SNF) eventually destined for long-term storage in a geologic repository. Since the transuranic (TRU) elements in the SNF present a proliferation risk, limit the loading in the repository, and are the major contributors to the longterm toxicity and dose from the repository, the AFCI program is studying ways to reduce the amount of TRU that will eventually require storage. Several options to achieve this objective are being examined in the AFCI program, including "burning" the TRU in commercial LWRs and fast reactors. Fuel forms under consideration for LWRs include MOX and IMF. Low fertile IMF has been proposed for use in many forms and studied by several researchers. Inert matrix fuel offers offers several advantages relative to MOX, principally a greater degree of reduction in the TRU since no new TRU is produced in this fuel form. Currently, the AFCI LWR transmutation fuel development program plans to test both MOX and IMF in an irradiation test, designated LWR-2, in the United States Advanced Test Reactor, located at the Idaho National Laboratory. The goal of the AFCI LWR transmutation program is to develop a fuel composition that fulfills four general criteria:

1. The fuel must provide for reliable power production in a LWR similarly to standard uranium-oxide (UOX) fuel.

2. The fuel composition must provide for the destruction of actinide species ( $\mathrm{Pu}, \mathrm{Am}$, and $\mathrm{Np}$ ) in a proliferation resistant form.

3. The fuel must perform these functions without greatly increasing the fissile material loading (which affects fuel cycle cost) in the overall nuclear fuel cycle, and should be within the existing safety envelope of commercial LWRs.

4. The fuel composition must allow for extraction and processing to recover the heavy metal for possible further destruction (via re-cycling into LWRs or fast reactors) or treatment for ultimate burial in a geologic repository.

To provide for flexibility in the incorporation of plutonium/actinide bearing fuels in pressurized and boiling water reactors, a variety of MOX and IMF compositions are being proposed for inclusion in the planned AFCI irradiation experiment, LWR-2. A variety of compositions are needed to determine the feasibility and performance of fuels containing significant amounts of TRU, and allow for flexibility in loading strategies for fuel management. This paper will explore the general neutronic and thermal hydraulic performance of transmutation fuels based on the low fertile matrix material $\mathrm{MgO}-\mathrm{ZrO}_{2}$. For comparison the neutronic and thermal hydraulic performance characteristics of UOX, Yittria-Stabilized $\mathrm{ZrO}_{2}$ and $\mathrm{SiC}$ fuels are presented.

A variety of inert matrix materials have been proposed and studied for use in high burnup actinide

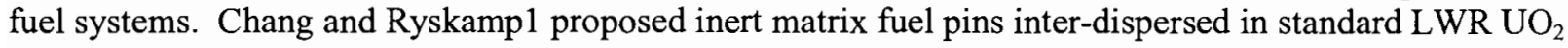
fuel bundles to achieve burnup and destruction of Pu material without negatively impacting operational characteristics of LWR operation. Herring et al.2 proposed a $\mathrm{ThO}_{2}$ based transmutation fuel for LWR systems to eliminate the $\mathrm{U}^{238}$ matrix from the reactor system entirely. Eaton, et al.3 proposed a full inert matrix of $\mathrm{ZrO}_{2}$ stabilized with $\mathrm{CaO}$ and loaded with TRU. Much work has been performed in the YtO stabilized $\mathrm{ZrO}_{2}$ matrix system for application to once-through then out (OTTO) fuel cycles, Schram4 and Ledergerber5. Irradiation and property test programs performed on the Yttria stabilized zirconia (YSZ) matrix have indicated excellent stability and performance both as a fuel system and as a final waste form meeting repository waste disposal criteria. In a once through fuel application Hellwig et al.9 irradiated a Yittria stabilized $\mathrm{ZrO}_{2}$ matrix. The study compositions attained $440 \mathrm{kWd} / \mathrm{cm}^{3}$ burnup with no measurable 
fission gas release. The composition densified to $100 \%$ TD and pellet centerline temperature was found to be approximately 300 to $400^{\circ} \mathrm{C}$ higher than a comparable MOX fuel center-line temperature.

To implement an inert matrix fuel composition in the U.S. commercial LWR fleet, the matrix composition must be stable in water, and have a thermal conductivity higher than that found in the cubic $\mathrm{ZrO}_{2}$. Preliminary property tests and fabrication trials by Medvedev 6, 7 at the Idaho National Laboratory have indicated that the performance of a dual-phase $\mathrm{MgO}-\mathrm{ZrO}_{2}$ matrix may be able to meet the requirements of the AFCI LWR fuel program. The AFCI LWR fuel development program intends to fabricate and test a variety of fuel $\mathrm{MgO}-\mathrm{ZrO}_{2}$ compositions in an irradiation campaign in the Advanced Test Reactor in late 2006. The test will contain both IMF compositions and MOX fuel compositions for comparison. Some of the tested compositions will also include americium and neptunium to investigate effect of minor actinides on the fuel matrices.

Fuel compositions actually employed in LWR transmutation fuels will be significantly affected by what TRU streams can be easily extracted in the separations process. The "natural" streams are $\mathrm{Pu}$ (which would not be allowed from proliferation concerns), $\mathrm{Np}+\mathrm{Pu}$ (which is considered to have enhanced proliferation resistance; this fuel will result in some $\mathrm{Am}$ being present from the decay of $\mathrm{Pu}^{241}$ after separation thru fabrication and prior to reactor insertion), and $\mathrm{Np}+\mathrm{Pu}+\mathrm{Am}$. Current plans do not envision the inclusion of Curium. Error! Reference source not found.Table 1 presents a summary of the currently planned fuel compositions in the LWR-2 test series.

The $\mathrm{MgO}-\mathrm{ZrO}_{2}$ dual phase ceramic provides a combination of the properties of $\mathrm{MgO}$ and of $\mathrm{ZrO}_{2}$ that may be able to fulfill the goals of the U.S. LWR transmutation fuel program. When combined in the dual phase ceramic, the high thermal conductivity of $\mathrm{MgO}$ tends to overcome the poor thermal conductivity of $\mathrm{ZrO}_{2}$, Medvedev 7. The addition of $\mathrm{MgO}$ to $\mathrm{ZrO}_{2}$ in significant quantity has been found to increase the thermal conductivity of the matrix material greater than standard UOX or MOX fuel compositions. The stability of $\mathrm{ZrO}_{2}$ in water tends to overcome the dissolution of $\mathrm{MgO}$ in water. Having the ability to balance the thermal conductivity of the fuel with the capability for dissolution makes the $\mathrm{MgO}-\mathrm{ZrO}_{2}$ ceramic a leading candidate for an inert matrix material. $\mathrm{MgO}$ and $\mathrm{ZrO}_{2}$ both are known to have acceptable irradiation performance and demonstrating the performance of a Pu-bearing $\mathrm{MgO}-\mathrm{ZrO}_{2}$ fuel composition with additions of $\mathrm{Am}$ and $\mathrm{Np}$ will facilitate selection of this composition for further development as a transmutation fuel for LWRs.

Due to the fission efficiency of reactor grade plutonium the use of burnable poisons will likely be required to control excess reactivity throughout the fuel life, control the power distribution within an acceptable range, and provide additional Doppler feedback in inert matrix fuel compositions. Erbium oxide may be added to the inert matrix fuel compositions to achieve these objectives. Porta and Asou8, recommend less than $3 \mathrm{wt} \%$ additions of erbia to the fuel matrix since additions of erbia tend to decrease thermal conductivity. Medvedev7 measured a depression in thermal conductivity of $\mathrm{MgO}-\mathrm{ZrO}_{2}$ with erbia additions and therefore these additions must be balanced.

To study these issues, a neutronic/thermal-hydraulic/transient screening analysis is conducted. The following sections present the analysis methodology and the results as applied to inert matrix compositions of interest with emphasis on the $\mathrm{MgO}-\mathrm{ZrO}_{2}$ system. 
Table 1. Proposed compositions to be included in the LWR-2 irradiation test.

\begin{tabular}{|l|l|l|}
\hline & \multicolumn{1}{|c|}{ Description } & \multicolumn{1}{c|}{ Composition } \\
\hline 2 pins & LWR-1a composition at high burnup & $(\mathrm{U}, \mathrm{Pu}) \mathrm{O}_{2}$ \\
\hline 2 pins & IMF replacement to MOX matrix & $(\mathrm{Pu}) \mathrm{O}_{2}-\mathrm{MgO}-\mathrm{ZrO}_{2}$ \\
\hline 2 pins & IMF replacement to MOX matrix, w/Np addition & $(\mathrm{Pu}, \mathrm{Np}) \mathrm{O}_{2}, \mathrm{MgO}_{\mathrm{ZrO}}$ \\
\hline 2 pins & MOX w/ Np,Am additions & $\left(\mathrm{U}, \mathrm{Pu}, \mathrm{Np}, \mathrm{Am} \mathrm{O}_{2}\right.$ \\
\hline 2 pins & IMF replacement to MOX w/Np, Am additions & $(\mathrm{Pu}, \mathrm{Np}, \mathrm{Am}) \mathrm{O}_{2}, \mathrm{MgO}_{2} \mathrm{ZrO}_{2}$ \\
\hline 1 pin & Silicon carbide inert matrix & $\mathrm{UO}_{2}-\mathrm{SiC}$ \\
\hline 1 pin & Advanced Pyrochlore 1 & $(\mathrm{Pu}) \mathrm{O}_{2}-\mathrm{MgO}-\mathrm{ZrO}_{2}-\mathrm{Nd}$ \\
\hline 1 pin & Advanced Pyrochlore 2 & $(\mathrm{Pu}) \mathrm{O}_{2}-\mathrm{MgO}-\mathrm{ZrO}_{2}-\mathrm{Yb}$ \\
\hline
\end{tabular}




\section{FUEL SYSTEM ANALYSIS}

To screen candidate inert matrix fuel compositions for potential use in LWRs an integrated methodology is used which considers neutronic, thermal-hydraulic, and transient/accident aspects. This paper presents the results of this screening analysis performed on one of the above inert matrix compositions $\left((\mathrm{Np}+\mathrm{Pu}+\mathrm{Am}) \mathrm{O}_{2}, \mathrm{MgO}-\mathrm{ZrO}_{2}\right)$, and compares the results to an analysis performed in a previous study by Todosow et al.10 which considered the same fuel with $\mathrm{UOX}, \mathrm{ZrO}_{2}$, and $\mathrm{SiC}$ matrix materials.

The reference core for this analysis is a typical 4-loop Westinghouse PWR with a power of 3400 MW(th) and 193-17 x 17 fuel assemblies. The reference fuel is low enriched $(<5$ w/o $) U^{235}$ uranium oxide capable of achieving an 18-month cycle, and a typical fuel management strategy with three batches, and once through then out with geological repository storage for the discharged SNF. Neutronic calculations are limited to an infinite array of fuel assemblies, and "colorset" geometries that model the four neighboring quadrants of four neighboring assemblies. Figure 1 is a colorset geometry representing three UOX assemblies and one IMF assembly. Note that the IMF assembly (upper-right) assumes an annular fuel rod with a central plug to compensate for the possible lower thermal conductivity of the inert matrix. While this is true for a pure $\mathrm{ZrO}_{2}$ matrix, it may not be necessary with other matrix materials as discussed earlier. The IMF fuel in all cases is assumed to contain $\mathrm{Np}, \mathrm{Pu}$, and $\mathrm{Am}$ in oxide form, with an isotopic distribution characteristic of the discharge fuel from an advanced LWR with a burnup of $\sim 50$ $\mathrm{GWd} / \mathrm{T}$, after seven years of cooling and post-fabrication. The neutronics calculations are supplemented by steady state thermal-hydraulics, and selected system transient/accident analyses. Using the results of these analyses, preliminary conclusions can be drawn regarding the viability of proposed MMF with respect to conventional (Pu-only) and modified (e.g., $\mathrm{Np}+\mathrm{Pu}, \mathrm{Np}+\mathrm{Pu}+\mathrm{Am}$ ) MOX and UOX fueled cores.

\subsection{Neutronic Performance Analysis of Candidate IMF Systems}

The reactor physics calculations presented here were carried out with the BOXER lattice physics code11 with nuclear data based on JEF1.1. The BOXER code and models have been extensively benchmarked against several standard nuclear design codes, with a variety of nuclear data libraries to qualify its use for these analyses. The analyses include evaluation of the moderator temperature coefficient (MTC), Doppler coefficient, soluble boron reactivity worth, coolant void coefficient, and control rod system reactivity worth, and reactivity vs. burnup. Rod-wise power distributions and kinetics parameters are also determined for use in the thermal-hydraulic and safety analyses. Kinetics parameters include: prompt neutron lifetime, delayed neutron fraction, and decay constant.

Results are shown in Figure 2 for the burnup in full power day verses the $\mathrm{K}_{\text {inf }}$ behavior for several matrix compositions of interest. Since the actinide loading for all IMF cases is the same, the results show that impact of different matrix materials on the cycle length is slight.

In addition to the achievable cycle length, typical reactivity and control coefficients were also evaluated and are shown in Table 2Error! Reference source not found.. The presence of $\mathrm{Pu}$ and other TRU isotopes is known to "degrade" some of these parameters relative to a conventional UOX-fueled system. In particular, the worth of soluble boron and control rods decreases with increasing loading of $\mathrm{Pu}$ and other TRU, and at sufficiently high loadings, the void coefficient becomes positive. Also shown are results for an IMF assembly with reactor-grade plutonium that is based on that employed in a full-core PWR design proposed by the Paul Scherrer Institute, as well as representative values for a reactor-grade$\mathrm{Pu}$ MOX assembly, and from the Safety Analysis Report. The results show that, as expected, the most significant impact of IMF fuel is a significant reduction in the Doppler coefficient due to the absence of fertile material like U-238, and the soluble boron worth relative to conventional uranium oxide fuel; the 
MTC and void coefficients do not differ significantly. The results for zirconium oxide and silicon carbide matrix materials are very similar. The IMF results with TRU for the MTC, the void coefficient, and the estimated control rod (Ag-In-Cd) are close to those obtained by the Paul Scherrer Institute. The Doppler coefficient is less negative, while the soluble boron worth is more negative than for the Paul Scherrer Institute design. These results suggest a TRU-IMF design similar to that considered here is feasible/viable for implementation in a LWR. The behavior for an $\mathrm{MgO}-\mathrm{ZrO}_{2}$ matrix is similar to the other IMF results. These results suggest that mixed cores of IMF and UOX assemblies are the most likely implementation approach in order to keep an existing LWR within its licensed safety envelope.

Table 2. Reactivity coefficients and control worths for Westinghouse $17 \times 17$ assembly for standard uranium oxide and inert matrix fuels (BOL).

\begin{tabular}{|c|c|c|c|c|c|c|}
\hline \multirow{2}{*}{ Reactivity Coefficients } & \multirow{2}{*}{$\begin{array}{l}4.3 \mathrm{w} / \mathrm{o} \\
\mathrm{UOX}\end{array}$} & \multicolumn{2}{|c|}{$\begin{array}{c}\mathrm{Np}+\mathrm{Pu}+\mathrm{Am} \text { from } \\
\text { ALWR }\end{array}$} & \multirow{2}{*}{$\begin{array}{l}\text { Paul Scherrer } \\
\text { Institute IMF } \\
\text { (Reactor-grade } \\
\text { Pu-Zr-Er) } \mathrm{O}_{2} \\
\end{array}$} & \multirow{2}{*}{$\begin{array}{c}\text { MOX } \\
\left(\begin{array}{c}7 \text { w/o of } \\
\mathrm{Pu})\end{array}\right.\end{array}$} & \multirow{2}{*}{$\begin{array}{c}\text { Ref. Safety } \\
\text { Analysis Report }\end{array}$} \\
\hline & & $\begin{array}{l}(\mathrm{TRU}- \\
\mathrm{Zr}) \mathrm{O}_{2}\end{array}$ & $\begin{array}{l}(\mathrm{TRU}) \mathrm{O}_{2^{-}} \\
\mathrm{SiC}\end{array}$ & & & \\
\hline \multicolumn{7}{|l|}{ No Soluble Boron } \\
\hline Void (pcm/\% void) & -139 & -106 & -109 & -105 & -105 & \\
\hline $\mathrm{MTC}\left(\mathrm{pcm} /{ }^{\circ} \mathrm{C}\right)$ & -37 & -33 & -33 & -35 & -41 & 0 to -72 \\
\hline Doppler $\left(\mathrm{pcm} /{ }^{\circ} \mathrm{C}\right)$ & -2.5 & -1.3 & -1.4 & -1.8 & -2.9 & -5.2 to -2.5 \\
\hline Boron Worth (pcm/ppm) & -8 & -3.1 & -3.1 & -2.4 & -2 & -16 to -8 \\
\hline $\begin{array}{l}\text { Estimated } 61 \text { control } \\
\text { rods worth }(\% \Delta \rho)\end{array}$ & -10 & -6 & -6 & -6 & & $\begin{array}{l}-9(\mathrm{BOC}) \text { to }-8.5 \\
\text { (EOC) }\end{array}$ \\
\hline \multicolumn{7}{|l|}{$500 \mathrm{ppm}$ of Soluble Boron } \\
\hline Void $(\mathrm{pcm} / \%$ void $)$ & -94 & -85 & -90 & -88 & & \\
\hline $\operatorname{MTC}\left(\mathrm{pcm}^{\circ}{ }^{\circ} \mathrm{C}\right)$ & -24 & -26 & -27 & -30 & & \\
\hline
\end{tabular}

Table 3. Fuel material thermal-hydraulic characteristics.

\begin{tabular}{|l|l|l|l|}
\hline \multicolumn{1}{|c|}{ Parameters } & \multicolumn{1}{|c|}{$\begin{array}{c}\text { PWR } \\
\left(\mathrm{UO}_{2}\right)\end{array}$} & \multicolumn{1}{c|}{ IMF $\left(\mathrm{ZrO}_{2} / \mathrm{MgO}\right)$} & \multicolumn{1}{c|}{$\begin{array}{c}\text { IMF } \\
(\mathrm{SiC})\end{array}$} \\
\hline Hot Pin Radial Peaking & $\begin{array}{l}1.674 \\
(1.5678 \times 1.068)\end{array}$ & $\begin{array}{l}1.980 \\
(1.5678 \times 1.263)\end{array}$ & $\begin{array}{l}1.980 \\
(1.5678 \times 1.263)\end{array}$ \\
\hline Fuel Thermal Conductivity, W/m-K & $\begin{array}{l}5.14(\text { at } 616 \mathrm{~K}) \\
2.98(\text { at } 1200 \mathrm{~K})\end{array}$ & 5 (constant) & $\begin{array}{l}25.12(\text { at } 673 \mathrm{~K}) \\
16.12(\text { at } 1273 \mathrm{~K})\end{array}$ \\
\hline Fuel Volumetric Heat Capacity, $\mathrm{J} / \mathrm{m}^{3}-\mathrm{K}$ & $3.14 \times 10^{6}($ at $673 \mathrm{~K})$ & $4.22 \times 10^{6}$ (constant) & $\begin{array}{l}\left.3.37 \times 10^{6} \text { (at } 600 \mathrm{~K}\right) \\
\left.4.01 \times 10^{6} \text { (at } 1200 \mathrm{~K}\right)\end{array}$ \\
\hline
\end{tabular}




\subsection{Thermal Performance Analysis of Candidate IMF Systems}

The thermal-hydraulic performance of a three UOX/1-IMF "colorset" assembly configuration was evaluated by using the COBRA-EN code 11. Minimum departure from nucleate boiling ratio (MDNBR) is used as a figure of merit for the margin to thermal limits in the hottest or highest power region of the core. The thermal conductivity of the fuel matrix does not enter into this analysis due to the steady state nature of the heat transfer. The MDNBR generally depends on the temperature of the clad surface at steady state which is dependent upon the heat generation rate in the fuel.

Table 3 presents a summary of the primary heat transfer parameters for the $\mathrm{UO}_{2}, \mathrm{MgO}-\mathrm{ZrO}_{2}$, and $\mathrm{SiC}$. The thermal conductivity of the fuel matrix does not greatly affect the MDNBR analysis due to the steady state nature of the analyses. The MDNBR generally depends on the temperature of the clad surface at steady-state which is dependent upon the heat generation rate found in the fuel. The heat generation rate depends on the fissile loading and the neutron density found in the reactor core. Hence, the matrix material generally only has an effect on the MDNBR as a result in changes in the power distribution. The analysis conducted for the purpose of this paper has found that the matrices of interest do not greatly affect the performance of the fuel when compared to a standard MOX composition. MOX is known however to generally operate from 200 to $300^{\circ} \mathrm{C}$ greater than a comparable UOX composition 5 .

\subsection{Transient/Safety Analysis of Candidate IMF Systems}

Transient/safety analyses are performed using the RELAP5-3D systems computer code [14] modeling selected scenarios taking a 4-loop PWR plant as the model. Accidents that have been considered include: (1) a loss-of-coolant accident in the cold leg of the primary loop; (2) loss of primary flow; and (3) loss of power transients for a mixed core containing three UOX and one IMF assemblies in a "colorset". Reactor kinetics was modeled by a point kinetics model with reactivity feedbacks from moderator void, moderator temperature, and fuel temperature (Doppler effect). A large-break loss of coolant accident was analyzed earlier. Three factors rise as key measures of inert matrix loaded core transient behavior; hot pin radial peaking, thermal conductivity, and fuel volumetric heat capacity. A fuel matrix with low thermal conductivity will end up having a higher peak clad temperature during transients (loss of cooling, etc.) due to its inability to transfer heat effectively to the clad-coolant boundary. This causes a higher rise in fuel temperature during the accident progression. Temperature rises higher than that experienced in standard UOX fueled reactor cores may compromise the safety envelope and therefore inert matrix fuel development generally focuses on inert matrix material compositions having thermal conductivity equivalent to or higher than that of UOX matrix fuel. As noted earlier, annular fuel pellets may also be used to reduce the maximum fuel temperature. Other factors such as differences in the reactivity coefficients, kinetics parameters and control worths will have an effect on the progression of the accident (e.g., power profile, effectiveness of scram)

As illustrated above the general neutronic and thermal-hydraulic performance of the candidate IMF compositions does not depend greatly on the thermal conductivity of the matrix. Thermal conductivity does however, play an important role in the transient behavior of the fuel and the thermal conductivities of the proposed compositions vary significantly. Thermal conductivity generally governs the rate at which decay heat is transferred to the clad/coolant boundary and hence affects the rate at which a reactor core cools during a transient scenario. The three accidents analyzed for this paper illustrate the potential impacts of introducing IMF into an LWR. Key results are discussed to demonstrate the influence of performance parameters on the progression and consequences of various accident scenarios. 
To illustrate the behavior of the candidate IMF materials, Figure 3 shows a comparison between peak clad temperature (PCT) for the hot pin for a UOX loaded core and the hot pin for the IMF materials in a mixed UOX/IMF core using materials, $\mathrm{ZrO}_{2}-\mathrm{MgO}$ and $\mathrm{SiC}$ under a loss of coolant accident.

In a mixed UOX/IMF core, the relative magnitude of the PCT in the IMF and the UOX hot assembly is a direct consequence of the core power distribution. In the RELAP5 model, the hottest fuel pin shares the same coolant channel with the rest of fuel pins in the hottest fuel assembly. Thus the PCT is a function of both the pin power and the hot assembly power which determines the bulk coolant temperature experienced by the hot pin. According to the result of the "colorset" calculation each UOX assembly generates more power than the surrounding IMF assembly. On the other hand the peak fuel pin in the "colorset" is found in the IMF assembly. Thus the hottest fuel pin in the core is located separate from the hottest fuel assembly in the core. The RELAP5 results indicate that the maximum PCT in a loss of coolant accident occurs in the hottest UOX assembly in a mixed core. Because of the lower power in the IMF assembly the PCT for IMF is lower than the corresponding PCT for the UOX assembly.

In comparing the PCT for the UOX fuel in a mixed core and the PCT for the UOX fuel in a standard PWR it is noted that the pin-wise power distribution is more uniform in the fuel assemblies of a standard PWR. This results in the $\mathrm{UO}_{2}$ fuel in a standard PWR having a lower PCT than that for the UOX assembly in a mixed core.

In addition to a loss of coolant accident, two additional transients have been analyzed for the mixed UOX/IMF cores and a standard PWR UOX core. The two transients are loss of power and loss of primary flow. Figure 4 shows the PCT behavior with time under loss of power and loss of primary flow scenarios. A loss of power transient assumes tripping of the primary pumps, the turbine and the main feedwater pumps, followed by a reactor trip. After 75 seconds from the reactor trip only the emergency feedwater pump is assumed to inject emergency feedwater to the four steam generators. The PCT in this transient experienced an initial decrease after the reactor trip followed by a slow increase due to a reduction in heat removal by the steam generators. The upward trend of the PCT was finally mitigated by the injection of emergency feedwater that restored the heat removal capacity of the steam generators.

A loss of primary flow transient was initiated by a trip of the primary pumps at time zero, followed by a reactor trip at $87 \%$ flow. There was about a 5 -second delay in the reactor trip while the core flow is reduced due to the pump trip. With a decrease in core flow the core coolant temperature began to rise. The negative moderator temperature coefficient then added negative reactivity to the core. This was reflected in a downward drift in core power before the reactor trip shown in Figure 5. It is also of interest to note the responses of the fuel temperature for different fuel compositions. In general a fuel with higher thermal conductivity will have a lower fuel temperature as shown in Figure 6 indicative of its ability to transfer heat to the clad/coolant boundary. 


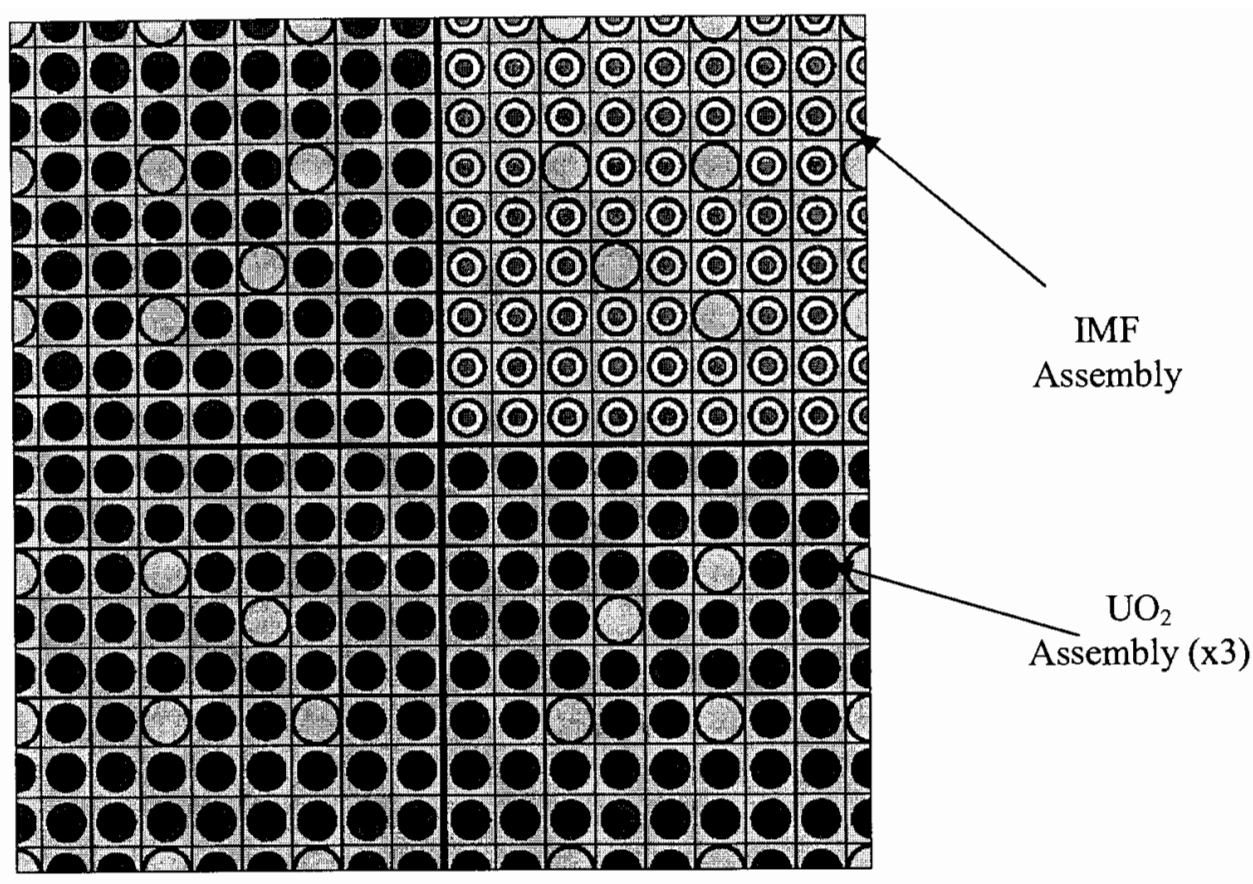

Figure 1. MCNP colorset geometry for (1-IMF/3-UOX) assemblies.

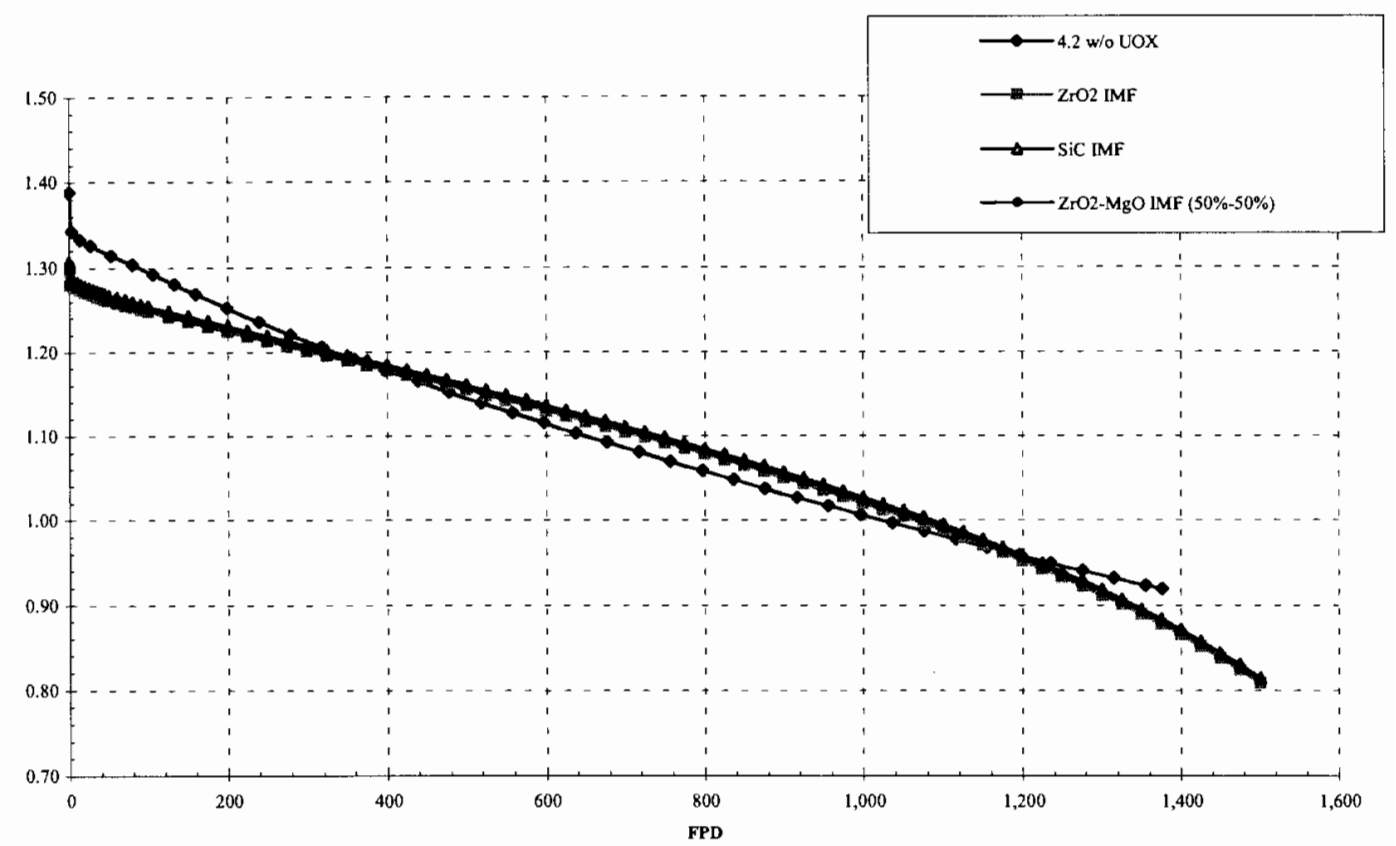

Figure 2. Kinf vs. full power day burnup graph comparison with Np-Pu-Am-MOX and UOX. 

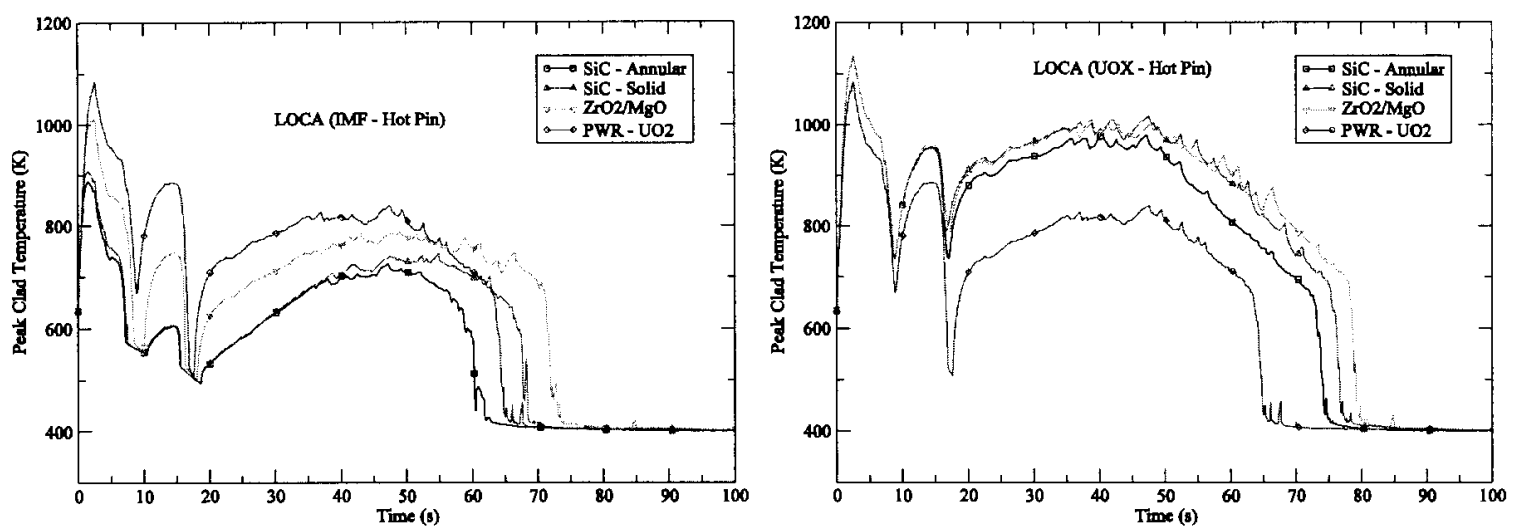

Figure 3. Peak clad temperature for hot pin comparison between $\mathrm{MOX}$ and $\mathrm{ZrO}_{2} / \mathrm{MgO}$ and $\mathrm{SiC}$ inert matrix materials.
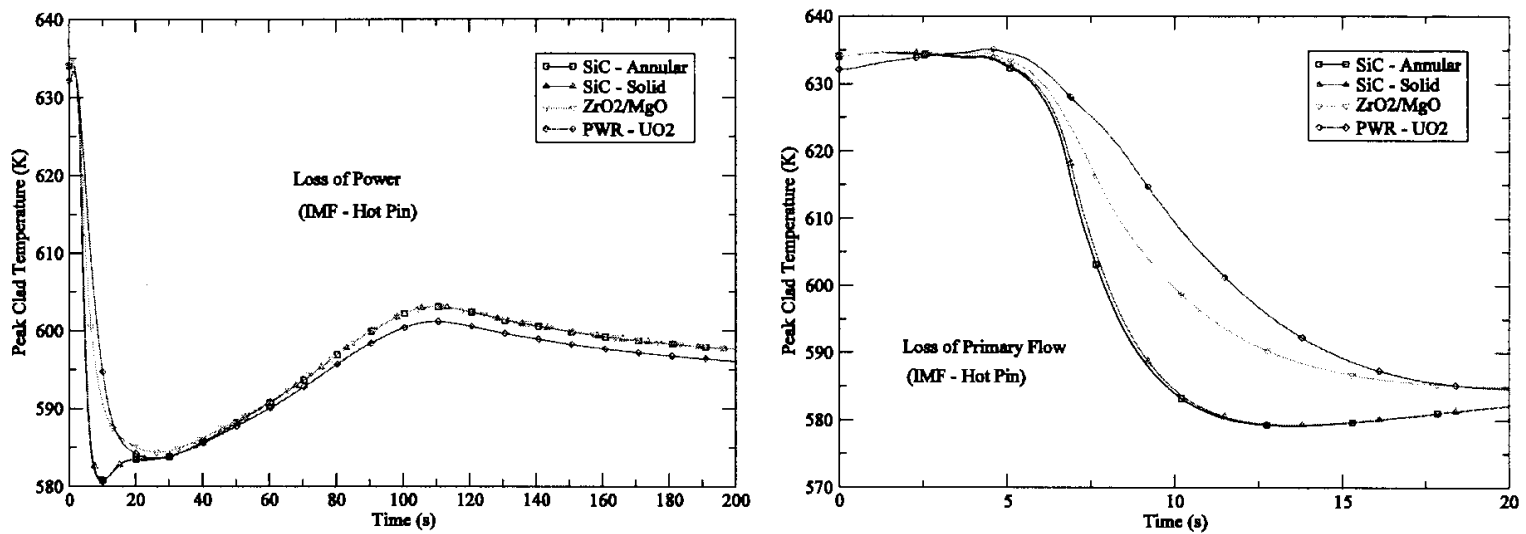

Figure 4. Peak clad temperature for hot pin for Loss of Power and Loss of Primary Flow transient. 


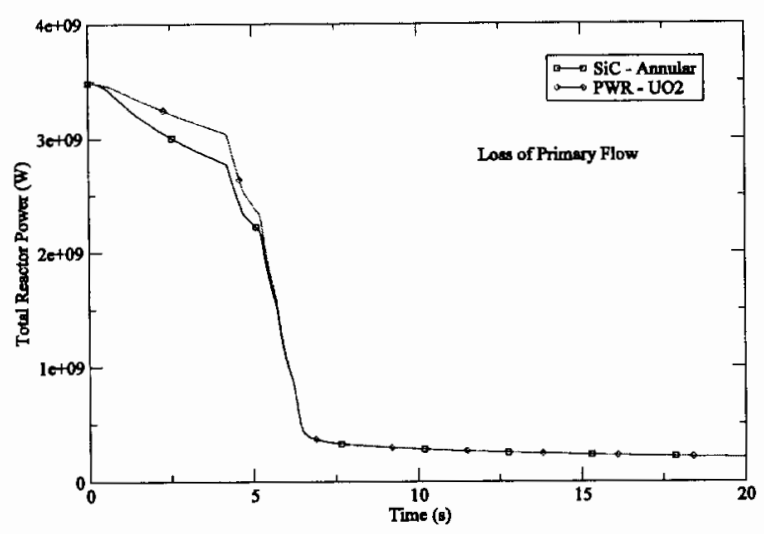

Figure 5. Reactor power under loss of flow transient.

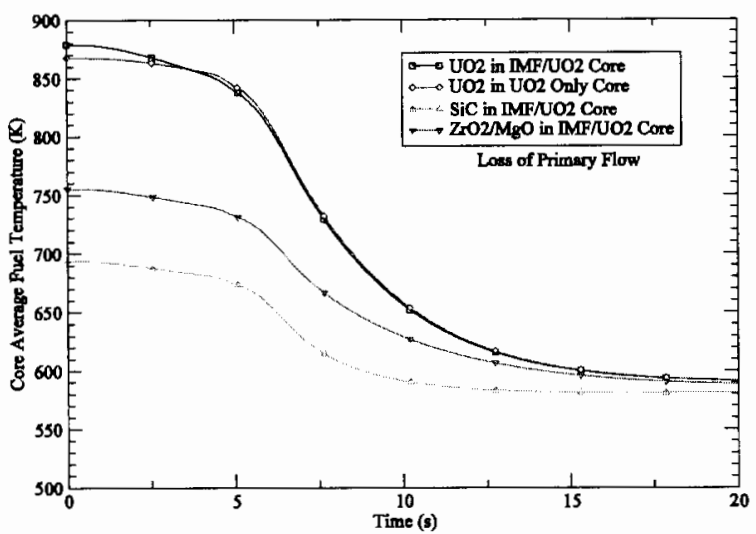

Figure 6. Core average fuel temperature under loss of flow.

The results of the Neutronic Performance Analysis show that there is no significant difference in the system criticality due to the matrix materials considered $\left(\mathrm{ZrO}_{2}, \mathrm{SiC}\right.$, or $\left.\mathrm{MgO}-\mathrm{ZrO}_{2}\right)$ assuming an $18-$ month operating cycle.

Other matrix materials such as $\mathrm{Zr}$-metal, $\mathrm{ZrO}_{2}-\mathrm{MgO}-\mathrm{CaO}, \mathrm{ZrO}_{2}-\mathrm{CaO}$ are potential candidates for additional consideration if the neutronic behavior is similar to that exhibited by the materials used in this study.

The matrix material composition and fissile loading should be defined basing on thermo-hydraulic analysis (heat flux, DNBR and fuel central-line temperature). The mechanical behavior of the fuel compositions under irradiation must be determined because the discharged accumulated burnup is very high and there is a high volumetric heat source in the fuel.

The choice of matrix materials is affected by whether a once-through or recycle scenario is desired.

The results for the reactivity coefficients and control worths show that the soluble boron worth of IMF is lower (very similar to MOX case) than for UOX standard fuel. In addition, the IMF fuel has significant low Doppler Coefficient. Using a burnable poison based on $\mathrm{Er}_{2} \mathrm{O}_{3}$ resonance absorber to significantly increase the Doppler coefficient will require compensating for the reduction in criticality with increased fissile loadings which may adversely affect other coefficients. Mixed UOX/IMF cores 
may be required to ensure that the reactor remains within its operational and safety envelope. Full threedimensional simulations of mixed cores must be performed to confirm these results.

Initial transient analysis shows that $\mathrm{ZrO}_{2}$ IMF fuel has higher peak clad temperature than UOX and $\mathrm{SiC}$ IMF fuel. The $\mathrm{MgO}-\mathrm{ZrO}_{2}$ thermal conductivity can be adjusted by varying the $\mathrm{MgO} / \mathrm{ZrO}$ ratio and measurements indicate that the achievable thermal conductivity is higher than the five $\mathrm{W} / \mathrm{m}-\mathrm{K}$ used in the calculations for this study. Initial analysis indicates that a 50/50 wt \% mixture of $\mathrm{MgO}-\mathrm{ZrO}_{2}$ results in peak clad temperatures similar to UOX. 


\section{FUEL SYSTEM FABRICATION DEVELOPMENT 4.1 MOX-Minor Actinide Fuel Development}

Mixed oxide fuel compositions have been developed and utilized in operating nuclear power plants around the world for several years. In fact the United States plans on destruction and utilization of approximately $30 \mathrm{MT}$ of weapons grade plutonium in MOX fuel assemblies in Catawba-1 Nuclear Power Plant beginning in 2005 or 2006. The history and data available for MOX fuel compositions makes it a logical choice for burning of Pu in LWR power systems. A logical extension of the traditional MOX fuel composition would be to test the effect under irradiation, the addition of Americium and Neptunium oxide to the fuel composition. For destruction of the minor actinides, the United States plans on testing traditional reactor grade MOX fuel containing additions of Americium and Neptunium oxide at quantities expect in recycled LWR spent nuclear fuel.

\subsection{Yttria Stabilized Zirconia Inert Matrix Development}

Yttria stabilized zirconia (YSZ) remains a matrix of choice for the disposition of plutonium and minor actinides in LWR. Despite extensive efforts on the production of this material at the ITU and also at Paul Scherrer Institute in Switzerland, high densities (95\% of the theoretical value [TD]) have been elusive. The achievement of this goal is of utmost importance, as licensing authorities will want to be sure that no appreciable fuel densification takes place during irradiation. This would cause an undesired increase in the fuel operating temperature. This series of tests at the ITU addresses the problem of improving the density from 90 to $95 \%$ TD in a reliable way. Using the combination of the sol gel external gelation process to produce highly porous beads, which are then infiltrated with the actinide, two solutions to remedy the low density were attempted:

- Milling of the particles produced by the sol gel process, to give a powder with better compaction properties

- $\quad$ Addition of carbon to the sol gel feed solution to produce softer particles for palletization 38

The former method can be used in the LWR2 program as the fuel does not contain americium. For applications with americium, the latter would be the preferred option. For the first time, ITU also studied the effect of erbium addition on the fabrication process. This will be required to provide a flatter power profile for the irradiation test.

Samples of pure yttria stabilized zirconia with erbium (YSZ-Er) have been fabricated by the sol gel external gelation process. The calcined $\left(800^{\circ} \mathrm{C}\right)$ beads had a polydisperse size distribution in the 40 and $150 \mu \mathrm{m}$ range. In a similar fashion highly porous beads were produced, but carbon powder was added to the sol gel feed solution and ultimately removed from the product in the calcination step. Such beads are "softer" for pressing purposes, and tend to avoid the so called "blackberry structure."

The YSZ-Er calcined beads were infiltrated with a cerium nitrate solution $\left(200 \mathrm{gCe} \cdot \mathrm{l}^{-1}\right)$ as a simulant for plutonium. Following evaporation of the water at room temperature, the infiltrated beads were heated to $800^{\circ} \mathrm{C}$ in air before their compaction using a biaxial press. Sintering was conducted in air, and the temperature was increased at a constant heating rate of $200^{\circ} \mathrm{C}$ /hour until $1650^{\circ} \mathrm{C}$, and was held at this temperature for six hours. Materials with the compositions given in Table 4 were prepared. 
Table 4. Ce content after infiltration.

\begin{tabular}{|l|l|l|l|}
\hline \multicolumn{1}{|c|}{ YSZ-Er } & \multicolumn{1}{c|}{ Ce content (\%wt) } & \multicolumn{1}{|c|}{ Compound } & \multicolumn{1}{c|}{ Code } \\
\hline $\begin{array}{l}\text { Carbon-free route } \\
(04 S G 036)\end{array}$ & 11.13 & $\left(\mathrm{Ce}_{0.104} \mathrm{Er}_{0.053} \mathrm{Y}_{0.101} \mathrm{Zr}_{0.742}\right) \mathrm{O}_{2-\mathrm{x}}$ & $04 \mathrm{~N} 049$ \\
\cline { 2 - 5 } & 10.10 & $\left(\mathrm{Ce}_{0.094} \mathrm{Er}_{0.054} \mathrm{Y}_{0.102} \mathrm{Zr}_{0.750}\right) \mathrm{O}_{2-\mathrm{x}}$ & $04 \mathrm{IN} 047$ \\
\hline $\begin{array}{l}\text { carbon-added route } \\
(04 \mathrm{SG} 037)\end{array}$ & 11.30 & $\left(\mathrm{Ce}_{0.106} \mathrm{Er}_{0.053} \mathrm{Y}_{0.101} \mathrm{Zr}_{0.740}\right) \mathrm{O}_{2-\mathrm{x}}$ & $04 \mathrm{IN} 050$ \\
\hline
\end{tabular}

The weight, dimensions and geometric density of the pellets are summarized in Table 5. It can be noted that increasing the pressure has a substantial effect on the density of the sintered pellets. This effect has recently been observed in the production of $(\mathrm{Zr}, \mathrm{Y}, \mathrm{Am}) \mathrm{O} 2$ pellets, where significant density improvements were found on pressing at $800 \mathrm{MPa}$, so that a green density close to $50 \%$ of the theoretical value was reached 39. XRD measurements are shown in Figure 7. The results indicated the formation of a solid solution $(\mathrm{Ce}, \mathrm{Er}, \mathrm{Y}, \mathrm{Zr}, \mathrm{O} 2-\mathrm{x})$ with a lattice parameter of $0.5172 \mathrm{~nm}$.

Table 5. Pelletisation of (Ce,Er, $, \mathrm{Y}, \mathrm{Zr}) \mathrm{O}_{2}$ beads.

\begin{tabular}{|c|c|c|c|c|c|c|}
\hline YSZ-Er & $\begin{array}{l}\text { Infiltrat. } \\
\text { code }\end{array}$ & Compound & Pellet code & & $\begin{array}{l}\% \mathrm{TD} \\
400 \mathrm{MPa}\end{array}$ & $\begin{array}{l}\% \mathrm{TD} \\
500 \mathrm{MPa}\end{array}$ \\
\hline \multirow[t]{2}{*}{ 04SG036 } & 04IN049 & $\left(\mathrm{Ce}_{0.104} \mathrm{Er}_{0.053} \mathrm{Y}_{0.101} \mathrm{Zr}_{0.742}\right) \mathrm{O}_{2-\mathrm{x}}$ & $04 \mathrm{MP} 130$ & Milling & & 97.2 \\
\hline & 04IN047 & $\left(\mathrm{Ce}_{0.094} \mathrm{Er}_{0.054} \mathrm{Y}_{0.102} \mathrm{Zr}_{0.750}\right) \mathrm{O}_{2-\mathrm{x}}$ & 04MP127 & - & 92.5 & 95.3 \\
\hline \multirow[t]{2}{*}{ 04SG037 } & \multirow[t]{2}{*}{ 04IN050 } & \multirow[t]{2}{*}{$\left(\mathrm{Ce}_{0.106} \mathrm{Er}_{0.053} \mathrm{Y}_{0.101} \mathrm{Zr}_{0.740}\right) \mathrm{O}_{2-\mathrm{x}}$} & 04MP131 & - & 90.9 & 96.0 \\
\hline & & & 04MP132 & Milling & & 95.6 \\
\hline
\end{tabular}




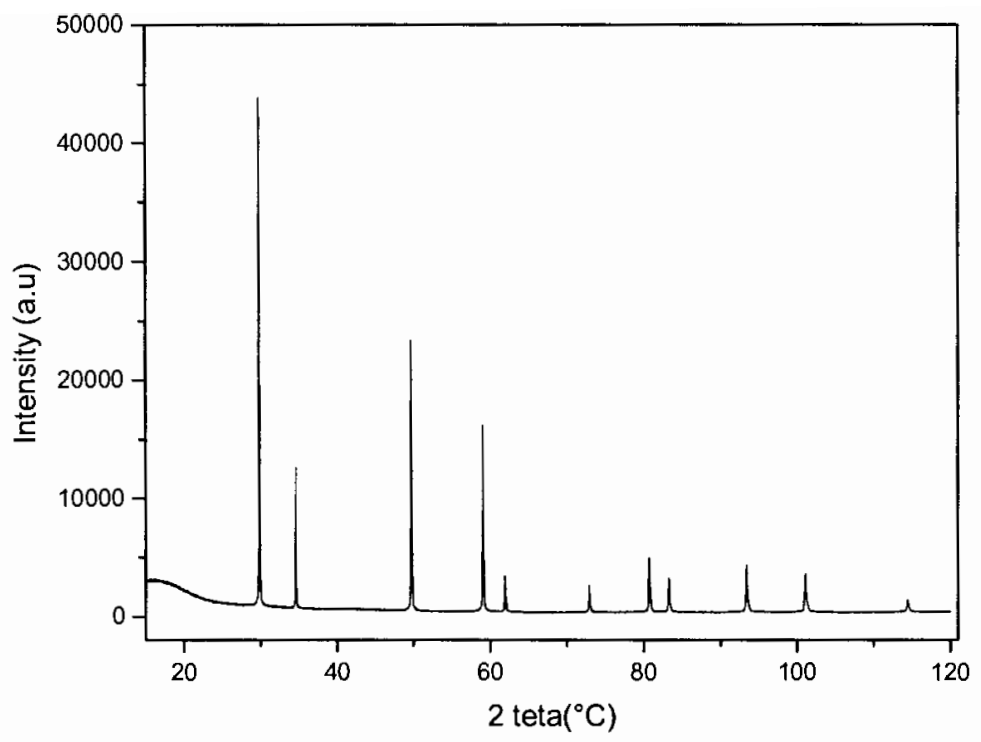

Figure 7. XRD pattern of sample 04MP130. Solid solution (Ce,Er,Y,Zr) $\mathrm{O}_{2}-\mathrm{X}$.

Micrographs of sectioned and polished pellet surfaces are shown in Figure 8. For the pellets fabricated from carbon-free beads the precursor spheres (blackberry structure) can be easily identified in the ceramograph, but to a much less extend following milling. When carbon is added, the microstructure of the pellets produced is highly improved respect to the carbon-free route. In contrast to the results in 38 the precursor beads are still recognizable. The reasons for this are unclear, but could be related to the presence of Er. Differences in the pressing characteristics of beads produced by the sol gel route have been encountered at the ITU and have usually been attributed to small but uncontrolled changes in the process parameters. Milling of these beads improves the porosity distribution dramatically. Further investigations are required to determine the residual carbon in the final product. The milling step is precluded for minor actinides, however, as dusts are produced. 


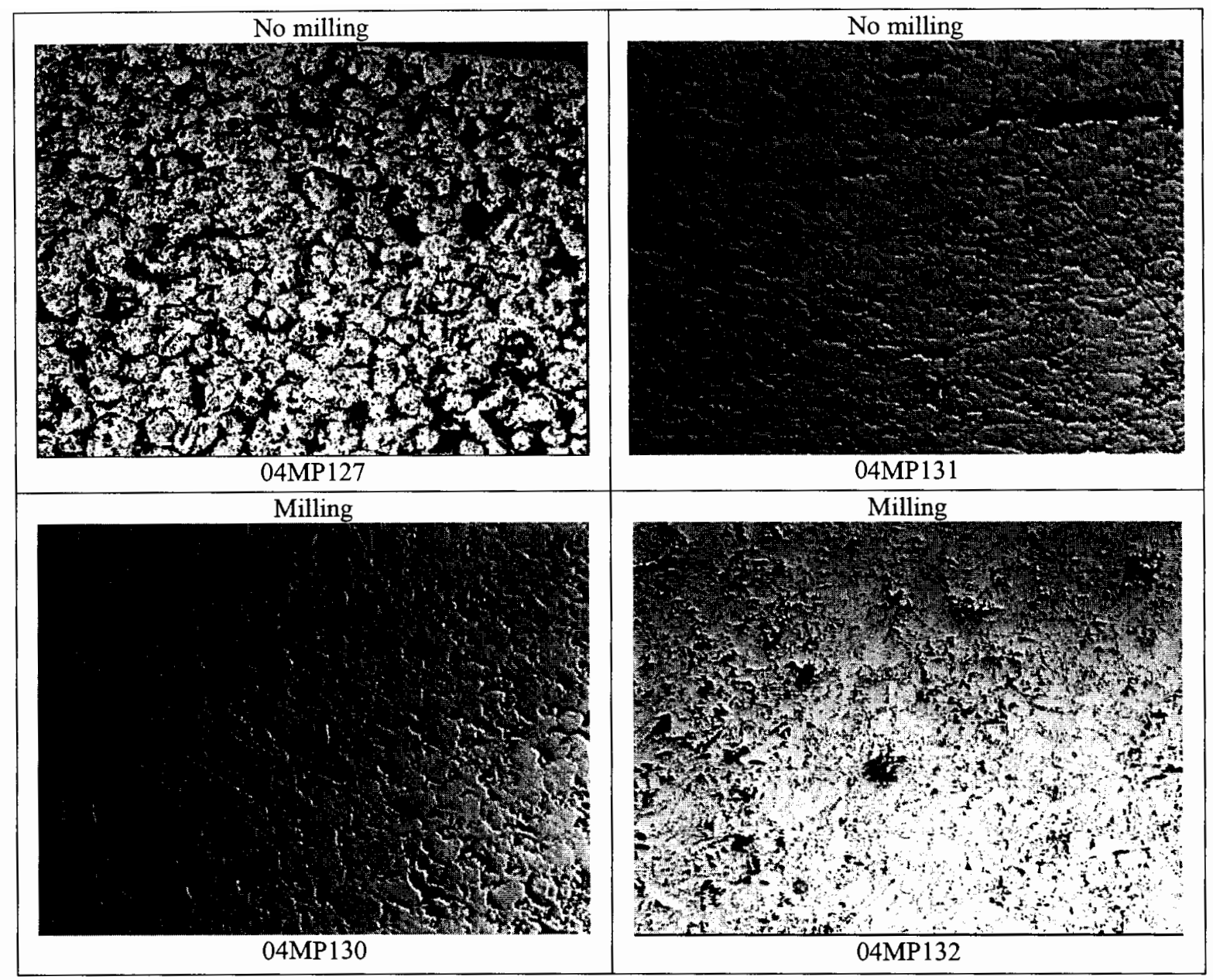

Figure 8. Optical micrographs of pellets fabricated by the free-carbon and added carbon route with and without an intermediate milling step.

\subsection{Dual Phase $\mathrm{MgO}_{\mathrm{Z}} \mathrm{rO}_{2}$ Inert Matrix Development}

$\mathrm{MgO}-\mathrm{ZrO} 2-\mathrm{PuO} 2$ ceramic composites are being studied as an inert matrix fuel (MF) form for LWRs. The motivation of this work is to develop an IMF with a thermal conductivity superior to that of the fuels based on yttria stabilized zirconia. The concept uses the $\mathrm{MgO}$ phase as an efficient heat conductor to increase thermal conductivity of the composite. In this paper ceramic fabrication and characterization by scanning electron microscopy, energy and wavelength dispersive $\mathrm{x}$-ray spectroscopy is discussed. Characterization shows that the ceramics consist of the two-phase matrix and $\mathrm{PuO} 2$-rich inclusions. The matrix is comprised of pure $\mathrm{MgO}$ phase and $\mathrm{MgO}-\mathrm{ZrO}_{2}-\mathrm{PuO}_{2}$ solid solution. The $\mathrm{PuO}_{2}$ rich inclusion contained dissolved $\mathrm{MgO}$ and $\mathrm{ZrO}_{2}$.

\subsubsection{Introduction}

Advanced fuel cycle initiative (AFCI) is being pursued by the United States Department of Energy with a four-prong objective: (1) recovery of energy from spent nuclear fuel (SNF), (2) reduction of the inventory of civilian plutonium, (3) reduction of the toxicity and heat load of stored SNF, and (4) more effective use of the SNF repository. AFCI's mission is to develop and demonstrate technologies that 
enable the transition to a stable, long-term, environmentally, economically, and politically acceptable fuel cycle.

Use of existing LWRs as a neutron source to fission plutonium and transmute minor actinides provides a near term opportunity for very effective in-reactor disposition of these surplus nuclear materials 15 . A need for a non-fertile matrix material that can be safely used in LWR fuels as plutonium and minor actinide dilutant drives material development research in this field.

Yttria stabilized zirconia (YSZ) is the most evolved candidate for use in IMF. Both steady-state 16 and transient 17 irradiations of YSZ-based IMF have been performed. Material properties of YSZ have been closely examined 18,19 . Out-of pile irradiation studies designed to understand the mechanism of radiation damage have been completed 20. Neutronic feasibility of YSZ-based IMF has been also assessed 21 complemented by core burnup calculations and accident analyses 22 . Despite its excellent radiation resistance, compatibility with reactor materials and good neutronic properties, very low thermal conductivity is the main disadvantage of YSZ. According to a recent analysis 21 fuel centerline temperature of the YSZ-based IMF may be $100^{\circ} \mathrm{C}$ higher than the limit specified for LWRs. Safe use of YSZ as a matrix in LWR fuel is only possible if a reactor is operated at a lower power or if fuel pellets feature central voids. Both measures increase the cost and decrease the feasibility of plutonium disposition.

Use of composites containing a phase with a higher thermal conductivity could improve performance characteristics of zirconia-based IMF. Use of $\mathrm{MgO}$ as such a phase has been proposed 23, 24. It has been shown 24 that dual phase $\mathrm{MgO}-\mathrm{ZrO}_{2}$ ceramics have the thermal conductivity superior to that of $\mathrm{UO}_{2}$ and have notable resistance to the water at the temperature of $300^{\circ} \mathrm{C}$ and pressure $8.6 \mathrm{MPa}$, making them attractive for use as an IMF matrix. Development of IMF based on $\mathrm{MgO}-\mathrm{ZrO}_{2}$ ceramics continues at Idaho National Laboratory with the support of the AFCI. The present paper describes results of the first experiment to fabricate and characterize $\mathrm{MgO}-\mathrm{ZrO}_{2}-\mathrm{PuO}_{2}$ ceramics as a potential IMF form for use in LWRs.

\subsubsection{Fabrication}

$\mathrm{MgO}-\mathrm{ZrO}_{2}-\mathrm{PuO}_{2}$ ceramics were fabricated from the oxide powder mixture using conventional pressing and sintering techniques. The fabrication process was based on the earlier work 24 that dealt with non-radioactive materials. The flow diagram of the fabrication process is shown in Figure 9.

Pre-weighed amounts of magnesia and magnesium zirconium oxide powders were combined with water in a beaker. The weight of water was approximately three times greater than the weight of the powders combined. The water and powder mixture was stirred using a magnetic stirring bar for six hours. The slurry was dried in air at $80^{\circ} \mathrm{C}$ for five hours. The resulting powder was transferred into an alumina crucible and heat-treated at $1000^{\circ} \mathrm{C}$ for five hours in a high temperature tube furnace. The ramp-up and ramp-down rates were $10^{\circ} \mathrm{C}$ per minute. Upon cool-down, zinc stearate (Fisher Scientific Fair Lawn, NJ Z-78-4, lot 871095 , UPS grade) in the amount of $1 \%$ by weight was mixed into the powder using a mortar and a pestle. The powder was then pressed into pellets with a force of $13.34 \mathrm{kN}$ using a cylindrical die of $12.72 \mathrm{~mm}$ diameter. Resulting $\mathrm{MgO}-\mathrm{ZrO}_{2}$ pellets weighing $3.8986 \mathrm{~g}$ and $3.3571 \mathrm{~g}$ were transferred into a glovebox. Once in the glovebox, the pellets were ground and $1.0265 \mathrm{~g}$ of $\mathrm{PuO}_{2}$ powder was mixed in using a mortar and pestle. The powder was then pressed into pellets with a force of $44.45 \mathrm{kN}$ using a cylindrical die of $12.72 \mathrm{~mm}$ diameter. Resulting pellets were ground into powder using a mortar and pestle. The powder was passed through a sieve with an aperture size of 250 microns. The mixture was pressed again into pellets with a force of $13.34 \mathrm{kN}$ using a cylindrical die of $12.72 \mathrm{~mm}$ diameter. The pellets were placed into an alumina crucible and sintered in air for 7.5 hours at $1700^{\circ} \mathrm{C}$ in a high temperature box furnace. The ramp-up rate was $10^{\circ} \mathrm{C}$ per minute up to $1000^{\circ} \mathrm{C}$ and $5^{\circ} \mathrm{C}$ per minute from 
$1000^{\circ} \mathrm{C}$ to $1700^{\circ} \mathrm{C}$. The ramp-down rate was $10^{\circ} \mathrm{C}$ per minute. The pellets were cooled in the furnace after sintering.

Magnesium oxide was procured from Cerac Incorporated (Milwaukee, WI, item M-1017, lot X25111, typically $99.95 \%$ pure). Magnesium zirconium oxide supplied by Alfa Aesar (Ward Hill, minor actinides, stock 12343 , lot C01E, $99.7 \%$ metals basis) was used as a source of zirconia. Use of magnesium zirconium oxide facilitated obtaining a homogeneous distribution of $\mathrm{MgO}$ and $\mathrm{ZrO}_{2}$ in the final product.

\subsubsection{Characterization of $\mathrm{MgO}-\mathrm{ZrO}_{2}-\mathrm{PuO}_{2}$ ceramics}

\subsubsection{Visual inspection, dimensions, weight and density}

Two ceramic pellets were fabricated. Photographs of the pellets are shown in Figure 10. Assintered pellets are shown in Figure 10a. Pellet cross-section exposed by cutting a pellet with a diamond saw is shown in Figure 10Figure b. Each pellet featured one crack near one face as illustrated in Figure $10 \mathrm{c}$.

The pellets were weighed and measured with a caliper. Results of the measurements are shown in Table 6. Pellet diameter was measured three times: in the mid-pellet and near each face. Pellet hourglassing developed during sintering was manifested by diameter decrease in the mid-pellet region.

Pellet density values derived from weight and volume and measured by water immersion technique are included in Table 6. The pellet density was significantly lower than that of $\mathrm{MgO}-\mathrm{ZrO}_{2}$ ceramics studied in the earlier work $24 . \mathrm{MgO}-\mathrm{ZrO}_{2}$ ceramics containing $50 \mathrm{wt} \%$ of $\mathrm{MgO}$ had the density of 4.39 $\mathrm{g} / \mathrm{cm}^{3}$ measured by water immersion.

\subsubsection{Scanning Electron Microscopy}

Scanning electron microscopy (Zeiss DSM960A digital scanning electron microscope), energy and wavelength dispersive $x$-ray analyses (Oxford Instruments, Freemont, CA) were carried out with an objective to identify the phases present in the ceramics and to determine chemical composition of each phase. Previous fabrication and characterization studies 24 established that $\mathrm{MgO}-\mathrm{ZrO}_{2}$ and $\mathrm{MgO}^{-} \mathrm{ZrO}_{2}-$ $\mathrm{Er}_{2} \mathrm{O}_{3}$ systems containing from 40 to $70 \mathrm{wt} \%$ of $\mathrm{ZrO}_{2}$ and $7 \mathrm{wt} \% \mathrm{Er}_{2} \mathrm{O}_{3}$ sintered in air at $1700^{\circ} \mathrm{C}$ consisted of two phases: zirconia-based cubic solid solution and pure cubic magnesia. The amount of magnesia dissolved in the zirconia-based cubic solid solution phase was $13-17$ mol\%. Erbia dopant preferentially dissolved in the zirconia phase. Presence of pure $\mathrm{MgO}$ phase in the ceramics had a positive effect on their thermal conductivity. The same effect is desired in the $\mathrm{MgO}-\mathrm{ZrO}_{2}-\mathrm{PuO}_{2}$ system. Thus, understanding the behavior of $\mathrm{PuO}_{2}$ dopant in the $\mathrm{MgO}-\mathrm{ZrO}_{2}$ system is of particular importance.

To produce a sample for the SEM the pellet was cut with a diamond saw yielding a disk approximately $2 \mathrm{~mm}$ thick. The disk was broken up to produce smaller fragments by tapping with a pestle. One of the resulting fragments was mounted in the epoxy and manually polished with the silicon carbide paper of 600,800 , and 1200 grit. The polishing time was kept to a minimum in order to reduce the personnel radiation exposure. The sample submitted for analysis is shown in Figure 11.

Figure 12 shows key microstructural features identified in the sample: a two-phase matrix (Figure 12a) and a $\mathrm{PuO}_{2}$-rich inclusion (Figure 12b). The matrix was found to consist of pure $\mathrm{MgO}$ phase (dark phase in Figure 12a) and $\mathrm{MgO}-\mathrm{ZrO}_{2}-\mathrm{PuO}_{2}$ solid solution (light phase in Figure 12a). Except for the greater porosity, the microstructure of the matrix was found to be virtually identical to that observed in $\mathrm{MgO}-\mathrm{ZrO}_{2}$ and $\mathrm{MgO}-\mathrm{ZrO}_{2}-\mathrm{Er}_{2} \mathrm{O}_{3}$ systems 24. The $\mathrm{PuO}_{2}$-rich inclusion shown in Figure $12 \mathrm{~b}$ contained 
$\mathrm{MgO}$ and $\mathrm{ZrO}_{2}$ with $\mathrm{PuO}_{2}$ being a dominant component. The columnar grains surrounding the $\mathrm{PuO}_{2}$-rich inclusion were believed to be formed due to significant variation of $\mathrm{ZrO}_{2}$ solubility in $\mathrm{PuO}_{2}$ with temperature. Examination of the $\mathrm{PuO}_{2}$-rich end of the $\mathrm{PuO}_{2}-\mathrm{ZrO}_{2}$ phase diagram 25 revealed that the solubility of $\mathrm{ZrO}_{2}$ in $\mathrm{PuO}_{2}$ increases from 20 to $60 \mathrm{~mol} \%$ with the increase of temperature from $1200^{\circ} \mathrm{C}$ to $1700^{\circ} \mathrm{C}$. Therefore, this variation in solubility caused diffusion of $\mathrm{ZrO}_{2}$ into the $\mathrm{PuO}_{2}$ particle during the furnace ramp-up and sintering, and rejection of $\mathrm{ZrO}_{2}$ by $\mathrm{PuO}_{2}$-rich particle during furnace ramp-down. Rejection of $\mathrm{ZrO}_{2}$ by the $\mathrm{PuO}_{2}$-rich particle caused particle densification which led to the formation of a gap between the particle and the matrix observed in Figure 12b.

Energy Dispersive X-ray Spectroscopy (EDS) was used to determine chemical composition of the phases present in the ceramics. Typical EDS spectra are shown in Figure 13. As evident from Figure 13, the matrix $\mathrm{Pu}$ content is higher in the vicinity of $\mathrm{PuO}_{2}$-rich inclusions. This observation suggests that the solubility limit of $\mathrm{PuO}_{2}$ in the matrix locations away from the inclusions was not reached. Thus, observed undesirable inhomogeneity is possibly due to inadequate mixing rather than the limited solubility of $\mathrm{PuO}_{2}$ in the matrix.

Detailed EDS results are shown in Table 7. EDS spectra were taken in 15 locations in $\mathrm{MgO}-\mathrm{ZrO}_{2}-$ $\mathrm{PuO}_{2}$ grains, 10 locations in $\mathrm{MgO}$ grains, and 5 locations in a $\mathrm{PuO}_{2}$-rich inclusion. Thus, the numbers in Table 7 are the averages and the standard deviations of these multiple measurements. It should be noted that our EDS system is not capable of quantifying the Pu content. As follows from Table 7, very small amounts of $\mathrm{ZrO}_{2}$ were detected in the $\mathrm{MgO}$ grains. This fact was attributed to the presence of $\mathrm{ZrO}_{2}$ in the neighboring $\mathrm{MgO}-\mathrm{ZrO}_{2}-\mathrm{PuO}_{2}$ grains and possibly to the contamination of the surface of the $\mathrm{MgO}$ grains during polishing. Absence of dissolved $\mathrm{ZrO}_{2}$ and $\mathrm{PuO}_{2}$ in $\mathrm{MgO}$ was additionally confirmed by wavelength dispersive spectroscopy.

\subsubsection{Conclusions}

$\mathrm{MgO}-\mathrm{ZrO}_{2}-\mathrm{PuO}_{2}$ ceramics were fabricated and characterized by SEM, EDS and wavelength dispersive spectroscopy. Ceramics were found to consist of the two-phase matrix and $\mathrm{PuO}_{2}$-rich inclusions. The matrix was comprised of pure $\mathrm{MgO}$ phase and $\mathrm{MgO}-\mathrm{ZrO}_{2}-\mathrm{PuO}_{2}$ solid solution. The $\mathrm{PuO}_{2}$-rich inclusion contained dissolved $\mathrm{MgO}$ and $\mathrm{ZrO}_{2}$. Based on the characterization work it was concluded that the fabrication process must be modified to achieve homogeneity of the product, reduce porosity, and produce an acceptable fuel form. Improved mixing and calcination of $\mathrm{PuO}_{2}$ powder together with $\mathrm{MgO}$ and $\mathrm{ZrO}_{2}$ will be utilized during fabrication of the next batch of the ceramics.

The results of this study provide valuable insight on the phase relations in the $\mathrm{MgO}-\mathrm{ZrO}_{2}-\mathrm{PuO}_{2}$ system. The study established that neither $\mathrm{PuO}_{2}$ nor $\mathrm{ZrO}_{2}$ dissolved in the highly thermally conductive $\mathrm{MgO}$ phase. By remaining free from dissolved species, the $\mathrm{MgO}$ phase is expected to maintain its high thermal conductivity acting as efficient means of increasing the thermal conductivity of the entire ceramic composite. 


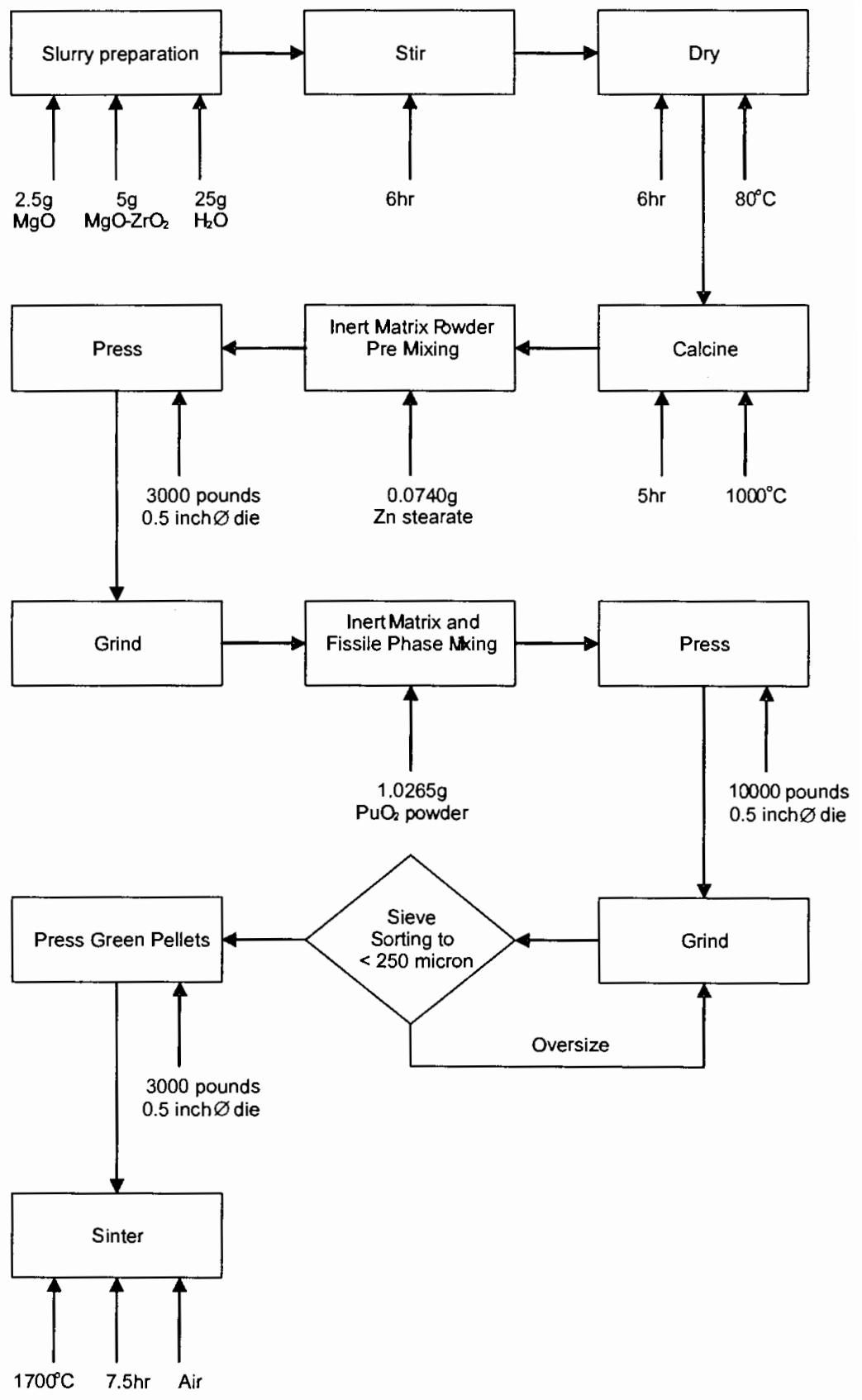

Figure 9. Flow diagram for fabrication of $\mathrm{MgO}-\mathrm{ZrO}_{2}-\mathrm{PuO} \mathrm{O}_{2}$ ceramics. 


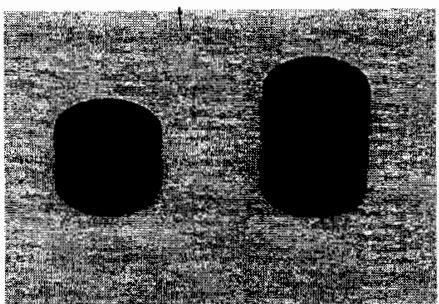

(a)

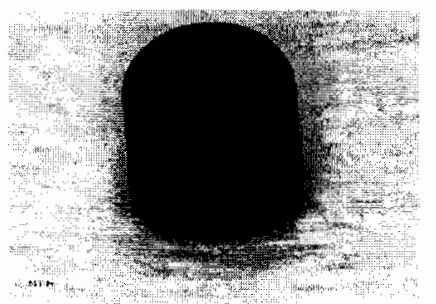

(b)

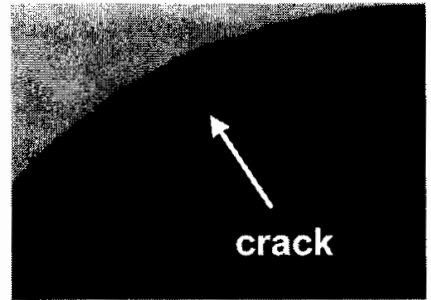

(c)

Figure 10. Fabricated $\mathrm{MgO}-\mathrm{ZrO}_{2}-\mathrm{PuO}_{2}$ ceramic pellets. (a) as-sintered pellets, (b) pellet cross-section, (c) crack near the face of the pellet.

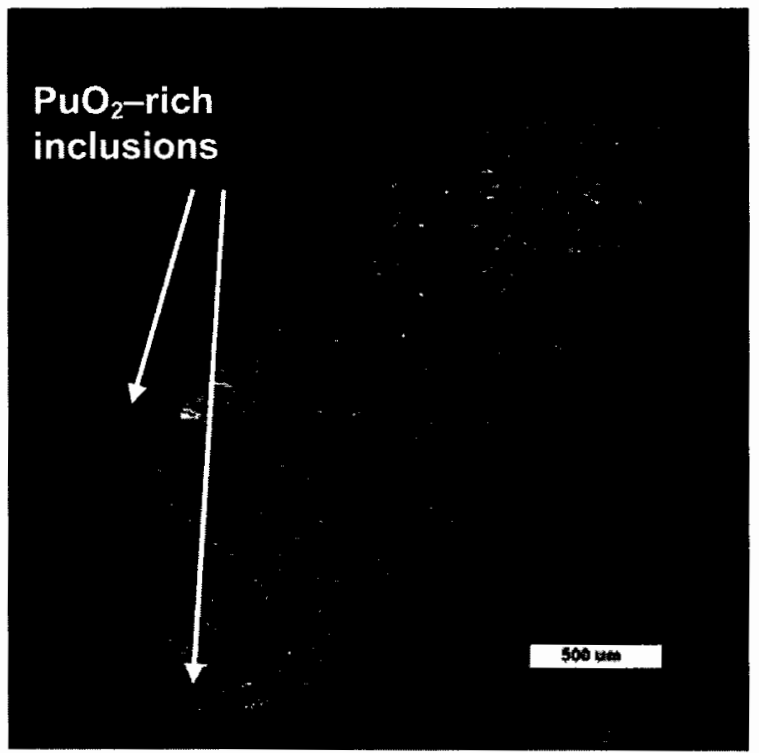

Figure 11. SEM image of the $\mathrm{MgO}-\mathrm{ZrO}_{2}-\mathrm{PuO}_{2}$ ceramic sample submitted for analysis. The black area surrounding and black shapes within the sample are the mounting epoxy. The sample consists of a matrix and $\mathrm{PuO}_{2}$-rich inclusions. 
(a)

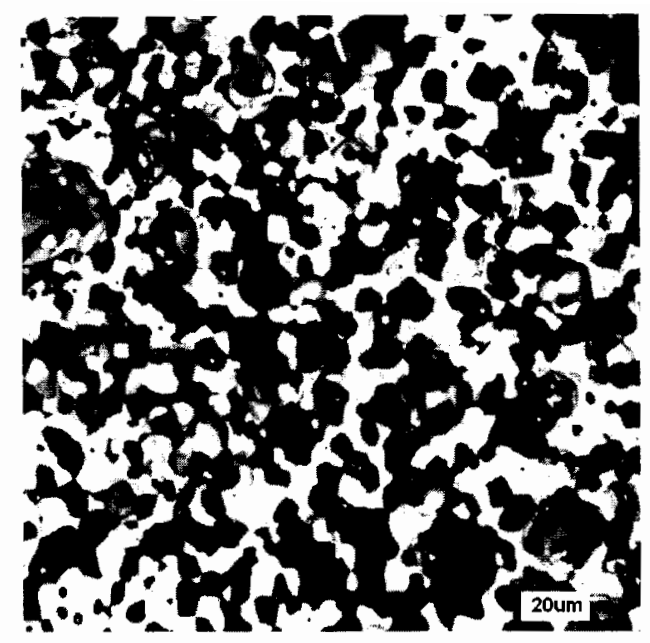

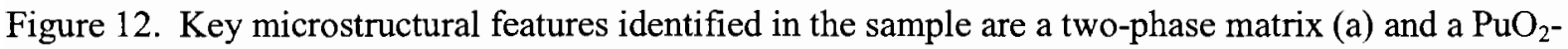
rich inclusion (b). The matrix consisted of pure $\mathrm{MgO}$ phase (dark phase) and $\mathrm{MgO}-\mathrm{ZrO}_{2}-\mathrm{PuO}_{2}$ solid solution (light phase). The $\mathrm{PuO}_{2}$-rich inclusion contained $\mathrm{MgO}$ and $\mathrm{ZrO}_{2}$ with $\mathrm{PuO}_{2}$ being a dominant component.
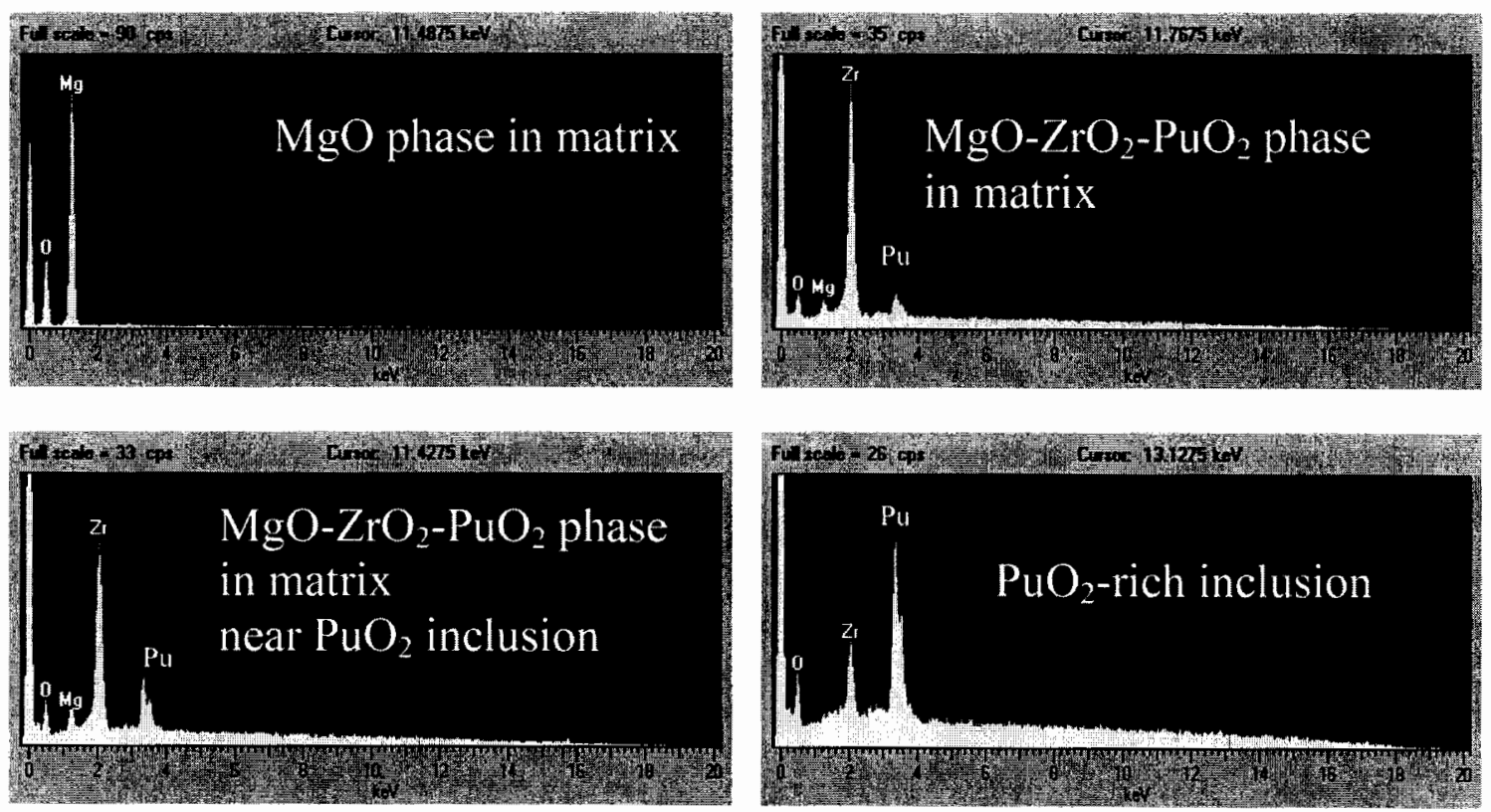

Figure 13. Typical EDS spectra observed in various locations in the ceramic. 
Table 6. Dimensions and weight of the sintered $\mathrm{MgO}-\mathrm{ZrO}_{2}-\mathrm{PuO}_{2}$ ceramic pellets.

\begin{tabular}{|l|l|l|l|l|l|l|l|l|}
\hline \multirow{2}{*}{ Pellet } & \multirow{2}{*}{ Weight, $\mathrm{g}$} & \multirow{2}{*}{ Length, $\mathrm{mm}$} & \multicolumn{2}{|l|}{ Diameter, $\mathrm{mm}$} & \multicolumn{2}{l|}{ Density, $\mathrm{g} / \mathrm{cm}^{3}$} \\
\cline { 5 - 10 } & & & face & mid-pellet & face & average & bulk & immersion \\
\hline 1 & 5.0406 & 13.00 & 11.59 & 11.40 & 11.60 & 11.53 & 3.71 & 3.8157 \\
\hline 2 & 2.9043 & 7.48 & 11.57 & 11.42 & 11.55 & 11.51 & 3.73 & 3.8751 \\
\hline
\end{tabular}

Table 7. Results from SEM EDS semi-quantitative analysis. Note that the ISIS EDS system cannot perform quantitative analysis for elements heavier than uranium.

\begin{tabular}{|l|l|l|l|l|}
\hline Phase & $\mathrm{Mg}$ (atomic\%) & $\mathrm{Zr}$ (atomic\%) & $\mathrm{O}$ (atomic\%) & $\mathrm{Zr}$ to Mg ratio \\
\hline $\mathrm{MgO}$ grains in matrix & $48.29 \pm 0.92$ & $0.06 \pm 0.04$ & $51.65 \pm 0.94$ & \\
\hline $\mathrm{MgO}-\mathrm{ZrO}_{2}-\mathrm{PuO}_{2}$ grains in matrix & $3.68 \pm 0.37$ & $23.19 \pm 1.10$ & $73.13 \pm 1.00$ & $6.38 \pm 0.83$ \\
\hline $\mathrm{PuO}_{2}$-rich inclusion & $0.91 \pm 0.32$ & $9.66 \pm 0.64$ & $89.43 \pm 0.87$ & $12.63 \pm 5.81$ \\
\hline
\end{tabular}

\subsection{Zr Metal Inert Matrix Dispersion Fuel Development}

$\mathrm{Zr}$ metal inert matrix dispersion fuels offer another novel approach to fulfilling the fuel requirements for a TRU-burning fuel in current and advanced LWR. Like many of the ceramic matrix based IMF fuels thermal conductivity is a major concern. In this regard $\mathrm{Zr}$ metal works well having a thermal conductivity at least as good as and in many cases better than most ceramic materials. This fuel form will also provide flexibility in the amount and composition of fuel phase that can be incorporated based on thermal and neutronic calculations. As noted in earlier sections in order to achieve adequate reactor control a burnable poison may need to be incorporated. It is currently anticipated that incorporation of a burnable poison into this fuel form will not present any significant fabrication issues. Currently fabrication research has been carried out at the Idaho National Laboratory using $\mathrm{ZrO}_{2}$ spheres as a surrogate fuel phase. Preparations are being made to carry out this work with enriched uranium as the fuel phase for possible inclusion in the LWR-2 irradiation test. This section will cover the fabrication work done up to this point in particular in regards to matrix fabrication/consolidation however, $\mathrm{UO}_{2}$ particle production will be discussed as well.

The basic fabrication route is quite simple a mixture or fuel particles and powdered zirconium are compacted into a hollow zirconium alloy (Zircaloy-4 is currently being used) billet. An additional amount of non-fueled zirconium or Zircaloy is compacted on top of the fueled section and the entire billet is then sealed in a copper can. The assembly is then extruded to a smaller diameter providing both consolidation of the matrix and fuel phase and bonding between all of the components. The following paragraphs will address these basic steps in more detail and give results of the on going development.

A cylindrical Zircaloy-4 (Zr-4) billet was fabricated by drilling out the center portion and tapering the front. This billet was then filled with zirconium powder and approximately 30 volume $\% \mathrm{ZrO}_{2}$ spheres with the top portion being filled only with zirconium powders with no spheres. Figure 14 shows a basic schematic of the prepared assembly, the assembly was then sealed in a copper can. The copper can provides both lubrication during extrusion and oxidation protection for the zirconium during heating and extrusion. A simple extrusion die was fabricated with a reduction from approximately 1 in. reduced to 0.4 in. (area reduction ration of approximately $6: 1$ ). The sealed assembly was placed in the die and the die heated to $750^{\circ} \mathrm{C}$ and allowed to soak approximately two hours. After soaking the die was moved to a 
large platen press which serves as a extrusion press and pressure was applied. The resulting extrusion was approximately 2 in. long, Figure 15.

Earlier extrusion attempts have been made using the same process however, the reduction was from 0.685 in. to $0.25 \mathrm{in}$. (area reduction ratio of 7.5:1) and niobium coated spheres were used. This extrusion attempt was also successful with approximately 4 in. of extruded material.

The niobium coating will be necessary on the final fuel to prevent interaction between the zirconium metal and uranium oxide. Traditional such coatings are applied through fluidized bed chemical vapor deposition. The coating used in these studies was applied following a powder metallurgical approach. The spheres and the powder were both well coated with a binder and placed in a rotating tumbler which contacted the two materials. The result was a very porous coating which could then be sintered. Although the sintered coating was very porous after sintering the extrusion process densified the coating to fully dense as seen under optical microscopy.

The extruded portion of the sample was characterized using optical microscopy. The matrix was fully dense and "fuel" particles mostly uniformly distributed throughout the interior, Figure 16. Also as can be seen from Figure 16 the $\mathrm{Zr}-4$ billet is very well bonded to the zirconium matrix with no voids being visible. In some areas it is visible that the spheres extruded into the cladding material, reducing the cladding thickness. Also behind some spheres a pore exists due to matrix material flow around the particles.

Neither the pore behind the sphere nor the reduced cladding thickness poses a significant challenge. One of the main advantages of the dispersion fuel is the fact that the fission product recoil damage is limited to a small volume of material. Even with these scattered pores this advantage is still in place. Also because the matrix is fully dense all fission gases will remain contained. Through the extrusion runs it has been observed that the spheres do not extrude into the cladding more than one-half of the diameter of the fuel sphere. This amount of reduced thickness can be compensated for by having a slightly larger cladding thickness, a reduced fuel sphere diameter, or it may also be improved by better extrusion parameter control.

Although not incorporated into the extrusion deplete $\mathrm{UO}_{2}$ spheres have been fabricated through rotating electrode atomization. In this process a feed pellet of $\mathrm{UO}_{2}$ is rotated at approximately 7000-10000 RPM and brought through an electric arc. The electric arc heats the material to melting and small droplets are flung off forming spheres before solidification. Figure 17 shows an example of the particles produced. As seen the particles are very spherical. The size distribution is uni-modal with one narrow peak. This peak can be moved to smaller or larger particle sizes based on the rotational velocity, higher velocities produce smaller particles. Sphere cross sections show a large shrinkage void in the interior of most spheres.

In conclusion a Zircaloy- 4 clad sample has been extruded with a zirconium matrix and zirconium oxide as a surrogate fuel phase. This has shown promise that a fuel bearing sample suitable for irradiation testing could be produced with little modification to the system. The zirconium matrix will contain the fission gases and, as a dispersion fuel, will have those attractive attributes to a dispersion fuel. Of these attributes one of the most important is the bulk of the matrix is not affected by fission fragment damage, therefore, properties such as thermal conductivity is not as severely degraded. Therefore the higher thermal conductivity of zirconium metal will lower the overall fuel temperature allowing for better fuel performance. Also similar dispersion fuels utilizing stainless steel as a matrix have been shown to be very robust, therefore as an actinide burning fuel form high actinide burning will be achievable. Although not traditional, spherical fuel particles have also been produced through rotating electrode atomization. These particles are uniform in size although a shrinkage void is present in the interior. 


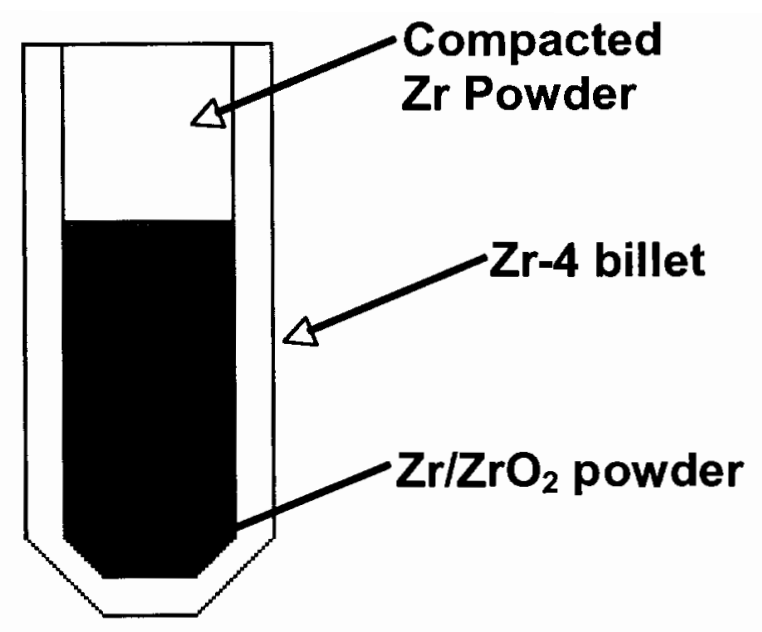

Figure 14. Schematic representation of the assembled $\mathrm{Zr}-4 / \mathrm{Zr}$ billet.

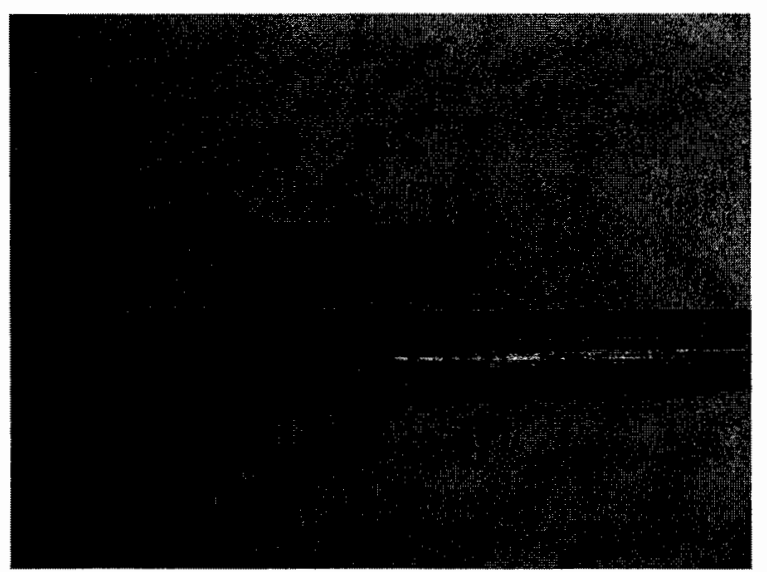

Figure 15. Photograph of 0.4-in. diameter $\mathrm{Zr}$ matrix dispersion "fuel" extrusion. 


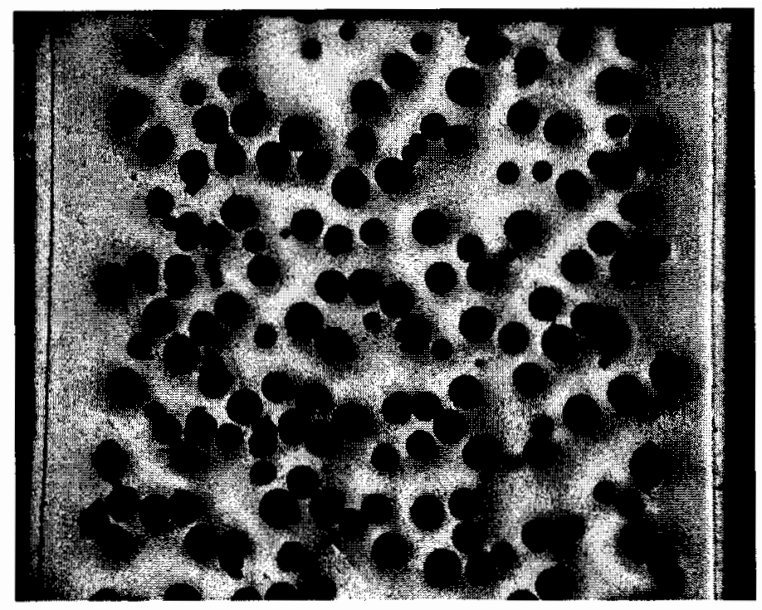

Figure 16. Photograph of 0.4-in. diameter $\mathrm{Zr}$ matrix dispersion "fuel" extrusion longitudinal cross section. Spheres measure approximately $0.5 \mathrm{~mm}$ in diameter.

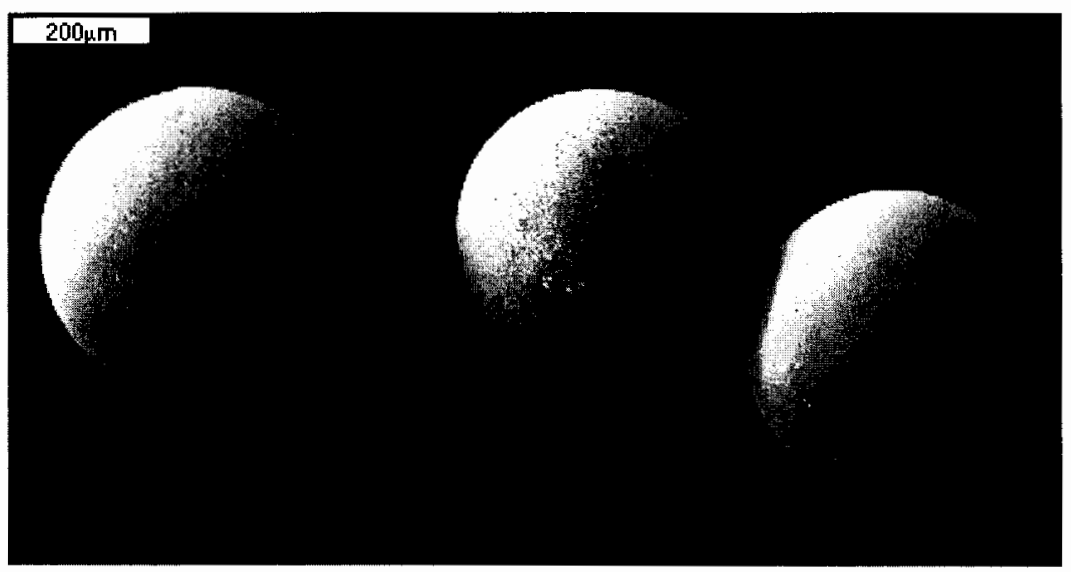

Figure 17. $\mathrm{UO}_{2}$ spheres produced through rotating electrode atomization. 


\section{REFERENCES}

1. G.S. Chang and J.M. Ryskamp, Nuclear Technology, 129, March 2000.

2. J.S. Herring, P.E. MacDonald, and K.D. Weaver, Nuclear Technology, 147, July 2004.

3. S. Eaton, C. Beard, K. Ramsey, J. Buksa, and K. Chidester, Nuclear Science and Engineering, 136, 2000, pp. 151-177.

4. Schram, et al., Progress in Nuclear Energy, 38, No. 3-4, 2001, pp. 259-262.

5. G. Ledergerber, C. Degueldre, P. Heimgartner, M.A. Pouchon, U. Kasemeyer, Progress in Nuclear Energy, 38, No. 3-4, 2001, pp. 301-308.

6. P. G. Medvedev, J. F. Jue, S. M. Frank, M. K. Meyer, "Fabrication and characterization of magnesia-zirconia-plutonia ceramics," E-MRS, IMF-10, Strasbourg, France, May 2005.

7. P. Medvedev, "Development of Dual Phase Magnesia-Zirconia Ceramics for Light-water Reactor Inert Matrix Fuel," Dissertation, Texas A\&M University, December 2004.

8. J. Porta and M. Asou, Progress in Nuclear Energy, 38, No. 3-4, 2001, pp. 347-350.

9. C. Hellwig, U. Kasemeyer, G. Ledergerber, B. Lee, Y-W Lee, R. Chawla, Annals of Nuclear Energy, 30, 2003, pp. 287-299.

10. M. Todosow, et al., "Initial Report on Safety and Licensing Issues Associated with the use of Inert Matrix Fuels in Light-Water Reactors (LWRs)," Brookhaven National Laboratory Report: BNLAFCI-2004-002, November, 2004.

11. J. M. Paratte, K. Foskolos, P. Grimm, C. Maeder, "The PSI Code System ELCOS for LWR Core Analysis," Paul Scherrer Institute, Villigen PSI, February 1996.

12. ORNL, "COBRA-EN: Code System for Thermal-Hydraulic Transient Analysis of Light-Water Reactor Fuel Assemblies and Cores," PSR-507, RSICC, May 2001.

13. INEEL, "RELAP5-3D Code Manual Volume 1: Code Structure, System Models and Solution Methods," INEEL-EXT-98-00834, Revision 2.2, October 2003.

14. "Reference Safety Analysis Report (RESAR-41)," Westinghouse Nuclear Energy Systems, December, 1973.

15. K.E. Sickafus, R.J. Hanrahan, K.J. McClellan, J.N. Mitchell, C.J. Wetteland, D.P. Butt, P. Chodak, K.B. Ramsey, T.H. Blair, K. Chidester, H. Matzke, K. Yasuda, R.A. Verrall, N. Yu, Burn and bury option for plutonium, Am. Cer. Soc. Bull. 78 (1), 1999, pp. 69-74.

16. Ch. Hellwig and U. Kasemeyer, "Inert matrix fuel performance during the first two irradiation cycles in a test reactor: comparison with modeling results," Journal of Nuclear Material, 319, 2003, pp. 87-94. 
17. T. Nakamura, H. Sasajima, T. Yamashita, and H. Uetsuka, "Morphology change of rock-like oxide fuels in reactivity-initiated-accident simulation tests," Journal of Nuclear Material, 319, 2003, pp. 95-101.

18. C. Degueldre, J. Paratte, "Basic properties of a zirconia-based fuel material for light-water reactors," Nuclear Technology, 123 (1), 1998. pp. 21-29.

19. C. Degueldre, T. Arima, Y. W. Lee, "Thermal conductivity of zirconia based inert matrix fuel: use and abuse of the formal models for testing new experimental data," Journal of Nuclear Material, 319,2003 , pp. 6-14.

20. K. Yasuda, C. Kinoshita, S. Matsumura, and A. I. Ryazanov, "Radiation-induced defect clusters in fully stabilized zirconia irradiated with ions and/or electrons," Journal of Nuclear Material, 319, 2003, pp. 74-80.

21. U. Kasemeyer, Ch. Hellwig, J. Lebenhaft, and R. Chawla, "Comparison of various partial lightwater reactor core loadings with inert matrix and mixed-oxide fuel," Journal of Nuclear Material, 319,2003 , pp. 142-153.

22. H. Akie, Y. Sugo, and R. Okawa, "Core burnup calculation and accidents analyses of a pressurized water reactor partially loaded with rock-like oxide fuel," Journal of Nuclear Material, 319, 2003, pp. 166-172.

23. . S. Lutique, R.J.M. Konings, V.V. Rondinella, J. Somers, T. Wiss, "The thermal conductivity of $\mathrm{Nd} 2 \mathrm{Zr} 2 \mathrm{O} 7$ pyrochlore and the thermal behavior of pyrochlore-based inert matrix fuel," J. of All. and Comp., 352, 2003, pp. 1-5.

24. P.G. Medvedev, "Development of dual-phase magnesia-zirconia ceramics for light-water reactor inert matrix fuel," Dissertation, Texas A\&M University, 2004.

25. P. G. Mardon, D. J. Hodkin, J. T. Dalton, "Some observations on the Pu-Zr-O system," Journal of Nuclear Material, 32, 1969, pp. 126-134.

26. W. J. Weber, J. W. Wald, H. Matzke, Journal of Nuclear Materials, 138, 1986 196-209.

27. H. Kamizono, I. Hayakawa, S. Muraoka, Journal of the American Ceramic Society, 74, 1991, pp. 863-864.

28. I. Hayakawa, H. Kamizono, Journal of Nuclear Materials, 202, 1993, pp. 163-168.

29. G. R. Lumpkin, K. P. Hart, P. J. Mcglinn, T. E. Payne, R. Giere, C. T. Williams, Radiochimica Acta, 66-7, 1994, pp. 469-474.

30. K. P. Hart, G. R. Lumpkin, R. Giere, C. T. Williams, P. J. McGlinn, T. E. Payne, Radiochimica Acta, 74, 1996, pp. 309-312.

31. P. E. Raison, R. G. Haire, Progress in Nuclear Energy, 38, 2001, pp. 251-254.

32. S. Lutique, R. J. M. Konings, W. Rondinella, J. Somers, T. Wiss, Journal of Alloys and Compounds, 352, 2003, pp. 1-5. 
33. S. Lutique, D. Staicu, R. J. M. Konings, V. V. Rondinella, J. Somers, T. Wiss, Journal of Nuclear Materials, 319, 2003, pp. 59-64.

34. K. E. Sickafus, L. Minervini, R. W. Grimes, J. A. Valdez, M. Ishimaru, F. Li, K. J. McClellan, T. Hartmann, Science 289 (2000) 748-751.

35. P. K. Schelling, S. R. Phillpot, R. W. Grimes, Philosophical Magazine Letters, 84, 2004, pp. 127137.

36. J. C. Nino, M. T. Lanagan, C. A. Randall, Journal of Materials Research, 16, 2001, pp. 1460-1464.

37. J. Payapilla, D. P. Butt, Journal of Nuclear Materials, submitted 2004.

38. J. Somers, A. Fernandez, "Fabrication routes for yttria stabilized zirconia suitable for the production of minor actinide transmutation targets," J. Am. Ceram. Soc., 88, 2005, pp. 827

39. A. Fernandez, D. Haas, J. Somers, unpublished results. 